\title{
Bromeliaceae da Mata AtLÂntica brasileira: LISTA DE ESPÉCIES, DISTRIBUIÇÃO E CONSERVAÇÃ̃ ${ }^{1}$
}

\author{
Gustavo Martinelli2,5, Cláudia Magalhães Vieira ${ }^{3}$, \\ Marcos Gonzalez ${ }^{2}$, Paula Leitman ${ }^{3}$, Andréa Piratininga ${ }^{3}$, \\ Andrea Ferreira da Costa \& Rafaela Campostrini Forzza $a^{2,5,6}$
}

\section{Resumo}

(Bromeliaceae da Mata Atlântica brasileira: lista de espécies, distribuição e conservação) A Mata Attântica está entre as mais importantes florestas tropicais do mundo, sendo considerada prioridade em termos de conservação devido a seu grau de ameaça e megadiversidade. Nesta floresta, Bromeliaceae é um dos grupos taxonômicos mais relevantes, devido ao alto grau de endemismo e expressivo valor ecológico decorrente principalmente de sua interação com a fauna. O presente trabalho tem por objetivo disponibilizar a lista de táxons de Bromeliaceae ocorrentes no domínio da Mata Atlântica no Brasil e o status de conservação de cada espécie de acordo com as listas oficias, bem como a distribuição destas nos estados e nos corredores da biodiversidade. Foram registrados 31 gêneros, 803 espécies e 150 táxons infraespecíficos. Os gêneros Andrea, Canistropsis, Canistrum, Edmundoa, Fernseea, Lymania, Nidularium, Portea, Quesnelia e Wittrockia são endêmicos do domínio e Vriesea (166 spp.), Aechmea (136 spp.) e Neoregelia (97 spp.) são os mais diversos. Também merecem destaque Alcantarea, Cryptanthus, Orthophytum e Neoregelia, que não são exclusivos da Mata Atlântica, porém, apresentam neste domínio seu centro de diversidade. Os estados da Região Sudeste somados ao sul da Bahia são os que abrigam a maior riqueza de espécies. Quanto ao status de ameaça, constatou-se que 338 táxons de Bromeliaceae encontram-se citados em listas oficiais de espécies ameaçadas. Os corredores da biodiversidade se mostraram de extrema relevância para a conservação da família, abrigando um grande número de espécies ameaçadas e endêmicas.

Palavras-chave: corredores de biodiversidade, espécies ameaçadas, endemismo.

\section{Abstract}

(Bromeliaceae of the brazilian Atlantic Forest: checklist, distribution and conservation) The Atlantic Forest is amongst the most important tropical forests in the world, being considered a priority for conservation due to the high degree of threat to its megadiversity. In this forest, Bromeliaceae is one of the most relevant taxonomic groups due to its expressive level of endemism and ecological importance mainly reflected by its manyfold relantionships with the local fauna. This work presents a species list of Bromeliaceae from the Atlantic Forest domain in Brazil together with their conservation status, as well as the distribution of species within states and biodiversity corridors. Thirty one genera were registered, with 803 species and 150 infraespecific taxa. The genera Andrea, Canistropsis, Canistrum, Edmundoa, Fernseea, Lymania, Nidularium, Portea, Quesnelia and Wittrockia are endemic to the domain, and Vriesea (166 spp.), Aechmea (136 spp.) and Neoregelia (97 spp.) are the most diverse. The genus Alcantarea, Cryptanthus, Orthophytum and Neoregelia are not exclusive to the Atlantic Forest, however they have their center of diversity in this biome. Brazil's southeast region plus southern Bahia state hold the highest species richness in the Atlantic Forest. Regarding the conservation status, 338 taxa of Bromeliaceae are cited in oficial lists of threatened species. The biodiversity corridors are extremely important for the conservation of the family, housing a great number of endemic and threatened species.

Key words: biodiversity corridors, threatened species, endemism.

\footnotetext{
Artigo recebido em 09/2007. Aceito para publicação em 02/2008.

${ }^{1}$ Projeto Financiado pelo Critical Ecosystem Partnership Fund (CEPF)

${ }^{2}$ Jardim Botânico do Rio de Janeiro, Pacheco Leão 915, 22460-030, Rio de Janeiro, RJ, Brasil

${ }^{3}$ Convênio JBRJ/Fundação Botânica Margaret Mee

${ }^{4}$ Museu Nacional/UFRJ, Quinta da Boa Vista, São Cristóvão, 20940-040, Rio de Janeiro, RJ, Brasil

${ }^{5}$ Autores para correspondência: gmartine@jbrj.gov.br - rafaela@jbrj.gov.br

${ }^{6}$ Bolsista de Produtividade CNPq
} 


\section{INTRODUÇÃ̃o}

A Mata Atlântica está entre as mais importantes florestas tropicais do mundo, sendo considerada prioridade em termos de conservação devido à grande fragmentação a que foi submetida, e que põe sob risco sua megadiversidade. Acredita-se que seus fragmentos guardem 20.000 espécies de plantas, das quais $40 \%$ são endêmicas (Myers et al. 2000). Ao longo dos anos seus limites foram amplamente discutidos e seu domínio foi interpretado sob os aspectos florístico, climático e biogeográfico (Cabrera \& Willink 1973; Rizzini 1997; Veloso et al. 1990; Leitão-Filho 1987; Oliveira-Filho \& Fontes 2000). Com o reconhecimento da sua heterogeneidade devido à presença de diversos ecossistemas associados, e de gradientes florísticos e climáticos, aproxima-se hoje de um consenso sobre seus limites (e.g. Oliveira-Filho $\&$ Fontes 2000; Fundação SOS/INPE 2000).

Inventários florísticos em diversos trechos do domínio Atlântico vêm apontando Bromeliaceae entre as famílias de maior riqueza e diversidade tanto genérica quanto específica (Barros 1991; Marques 1997; Lima \& Guedes-Bruni 1997; Araújo 2000; Costa \& Dias 2001; Mamede et al. 2001; Assis et al. 2004; Amorim et al. 2005; Martinelli 2006). Ainda que a maioria dos inventários florestais não inclua ervas, especialmente as epífitas, naqueles específicos desta forma de vida, as Bromeliaceae e Orchidaceae dominam as listas (e.g. Kersten \& Silva 2001; Borgo \& Silva 2003; Brogalski \& Zanin 2003; Giongo \& Waechter 2004).

No Brasil foram realizados alguns levantamentos e floras sobre a família dentro da Mata Atlântica (Reitz 1983; Fontoura et al. 1991; Wanderley \& Mollo 1992; Wendt 1994; Vidal 1995; Paula 1998; Sousa \& Wanderley 2000; Nunes-Freitas 2005; Pontes 2005; Versieux \& Wendt 2006; Vieira 2006; Barros 2006; Siqueira Filho \& Leme 2006; Leoni \& Trindade 2006; Costa \& Wendt 2007; Moura et al. 2007; Versieux \& Wendt 2007), além de trabalhos de cunho ecológico em comunidades (e.g. Martinelli 1998; Cogliatti-Carvalho et al.
2001; Fontoura 2005; Bonnet \& Queiroz 2006). No entanto, todos os esforços até então empreendidos para inventariar as Bromeliaceae na Mata Atlântica, são certamente insuficientes uma vez que o leste brasileiro é um dos principais centros de diversidade da família (Smith 1955).

Após a publicação da Flora Neotropica (Smith \& Downs 1974, 1977, 1979), avanços na taxonomia e na sistemática da família trouxeram um novo panorama especialmente com a publicação de mais de 900 espécies, 10 novos gêneros (Luther \& Sieff 1994, 1997; Luther 2001), e no realinhamento, particularmente, da subfamília Pitcairnioideae (Givnish et al. 2005).

Em relação à taxonomia das espécies brasileiras, diversos estudos têm sido direcionados para a revisão de gêneros, subgêneros e complexos de espécies (Wendt 1997; Leme 1997, 1998, 2000; Costa 2002; Tardivo 2002; Sousa 2004a; Sousa 2004b; Forzza 2005; Faria 2006; Siqueira Filho \& Leme 2006). Não obstante, ainda persistem lacunas de conhecimento, especialmente nos gêneros mais ricos (e.g. Aechmea, Vriesea, Tillandsia, Neoregelia). É notável na subfamília Bromelioideae a imprecisão nos limites genéricos, especialmente nos grupos relacionados a Aechmea (Faria et al. 2006), além dos inúmeros casos de imprecisão nos limites específicos (Faria 2006), sendo este último o principal problema também entre as Tillandsioideae (Costa 2002).

A importância de Bromeliaceae no cenário nacional da conservação da biodiversidade (Rocha et al. 1997; Martinelli 2006) e a necessidade de se reunir às informações taxonômicas após a publicação de Smith \& Downs (1974, 1977, 1979), foram os principais argumentos que motivaram a realização da presente listagem, uma vez que inúmeros trabalhos realizados com as Bromeliaceae nas diversas áreas do conhecimento podem valer-se das informações nela contida.

Listas de espécies ou checklists, tradicionalmente, são compostas por táxons 
encontrados em uma determinada área ou região geográfica, podendo ou não conter informações adicionais tais como a obra onde o táxon foi publicado, outras literaturas de referência, amostras examinadas, hábito, distribuição geográfica, preferências ecológicas, comentários taxonômicos, entre outras (GSPC 2005). A importância de checklists e floras, como ferramentas fundamentais para documentar a diversidade de plantas de uma região ou país, tem sido amplamente reconhecida (GSPC 2005; Clarke \& Funk 2005; IOPI 2006; SPECIES2000 2006). Assim, o principal objetivo do trabalho aqui apresentado é disponibilizar informações acerca da riqueza e a distribuição geográfica dos táxons nos estados e nos corredores da biodiversidade, bem como o status de conservação das espécies de Bromeliaceae na Mata Atlântica brasileira, possibilitando o acesso a estes dados de forma ágil e fácil por pesquisadores, gestores, estudantes, ambientalistas e pelo público interessado.

\section{Material e Métodos}

Os dados para a elaboração deste checklist foram obtidos através de expedições de coleta, levantamento das coleções, das bases de dados dos herbários disponíveis na internet e dos materiais citados na literatura procedentes de áreas inseridas no domínio da Mata Atlântica. Todos os espécimes foram reunidos no sistema de banco de dados utilizado pelo Jardim Botânico do Rio de Janeiro (JABOT). Para atender às demandas específicas do projeto, o banco foi adaptado, incorporando e padronizando alguns campos úteis às análises sobre conservação, como o status de conservação das espécies e informações acerca de seus hábitats. O algoritmo de georreferenciamento de corônimos foi incrementado, permitindo que as coletas pudessem ser localizadas da forma mais precisa possível em sistemas de informação geográfica (SIG).

Expedições para coleta de amostras foram feitas pelo Projeto Biologia e Conservação de Bromeliaceae da Mata Atlântica, no período de 1998-2001, abrangendo áreas consideradas mais representativas do domínio Mata Atlântica. Para tanto, foram percorridos 96.000 km desde o Ceará até o Rio Grande do Sul, englobando 14 estados brasileiros, sendo visitadas 78 Unidades de Conservação federais, estaduais e municipais e 59 áreas particulares. As expedições resultaram na obtenção de 1.073 amostras e um total de 300 táxons, todos incorporados ao herbário RB, com duplicatas enviadas a diversas instituições. Também foram incorporados 2.815 exemplares vivos no Bromeliário do JBRJ.

Foram consultados os acervos de 26 herbários, a saber: ALCB, CESJ, CVRD, EAC, EAN, FLOR, GFJP, GUA, HB, HBR, IPA, JPB, MAC, MBM, MBML, MOSS, PEUFR, R, RB, RBR, RFA, SP (em parte), SPF, UFP, UPCB e VIC (acrônimos segundo Holmgren \& Holmgren 1998). Também foram incluídos na base os dados cedidos pelo NYBG e os disponíveis no SpeciesLink do CRIA (www.cria.org.br). A obtenção dos espécimes citados na literatura baseou-se em Smith \& Downs $(1974,1977,1979)$ e publicações posteriores até dezembro de 2006 (livros, revisões, obras originais, teses e dissertações).

Os nomes dos táxons adotados na listagem tomaram por base Luther (2004) e as publicações posteriores a esta data até dezembro de 2006. Também foram utilizadas as referências de Luther \& Sieff $(1994,1997)$ e a lista de sinônimos de Marks (2006). Foram adotados os sinônimos propostos nas teses e dissertações de Costa (2002), Sousa (2004a), Sousa (2004b) e Faria (2006). Não foram incluídas espécies novas ou combinações novas propostas em dissertações e teses não validamente publicadas.

Para a delimitação do domínio Mata Atlântica utilizou-se o Atlas da Evolução dos Remanescentes Florestais e Ecossistemas Associados (Fundação SOS/INPE 2000), e o Mapa da Reserva da Biosfera (CN-RBMA 2004) que abrange 17 estados e 3.418 municípios e uma área de $2.062 .075 \mathrm{~km}^{2}$ do 
território brasileiro. A delimitação dos corredores da biodiversidade seguiu MMA (1998), Fonseca et al. (2004) e Ayres et al. (2005).

Dados acerca da distribuição geográfica por Unidade Federativa (UF) e ocorrência nos corredores da biodiversidade foram levantados em nível de espécie, uma vez que muitos exemplares de herbário examinados não se encontravam determinados a nível infraespecífico.

Para inclusão na lista foram considerados os táxons com ocorrência registrada na Mata Atlântica e seus ecossistemas associados, bem como áreas de encrave de cerrado ou campo rupestre, inseridos no domínio. Também foram incluídas as espécies que ocorrem em encraves de Mata Atlântica inseridos em outros biomas (e.g. brejos de altitude inseridos na caatinga). Para táxons ocorrentes em zonas de transição utilizou-se o critério de avaliação caso a caso, optando pela inclusão do táxon quando as informações disponíveis (literatura, herbários e experiência de campo) permitiram inferir sua ocorrência dentro do domínio atlântico.

Para classificar as espécies nas diferentes categorias de graus de ameaça, foram utilizadas as informações existentes nas seguintes listas federais e estaduais: do Rio Grande do Sul (SEMA 2002), de Santa Catarina (Klein 1990), do Paraná (SEMA 1995), de São Paulo (SEMA 2004), do Espírito Santo (IEMA 2005) e do Brasil (IBAMA 1992). Também foram utilizadas as listas elaboradas nos workshops organizados pela Fundação Biodiversitas para Revisão da Lista Oficial do Brasil (2005) e Revisão da Lista de Minas Gerais (2006) que foram encaminhadas para homologação, mas até a presente data não foram publicadas.

A versão final do banco de dados contendo cerca de 22.000 espécimes encontrase disponibilizada no endereço: http:// www.jbrj.gov.br/jabot/formularios/ projeto_brom_ma.php, permitindo o acesso ao material testemunho que serviu de base para a elaboração da presente lista.

\section{Resultados e Discussão}

Bromeliaceae conta atualmente com 56 gêneros e 3.086 espécies (Luther 2006). Na Mata Atlântica brasileira foi registrado um total de 31 gêneros, 803 espécies e 150 táxons infraespecíficos (Tab. 1). Dez gêneros (Andrea, Canistropsis, Canistrum, Edmundoa, Fernseea, Lymania, Nidularium, Portea, Quesnelia e Wittrockia) e 653 espécies são endêmicos dos domínios da Mata Atlântica. Os gêneros de maior riqueza de espécies são Vriesea (166 spp.), Aechmea (136 spp.) e Neoregelia (97 spp.) (Tab. 2). Também merecem destaque Alcantarea, Cryptanthus, Orthophytum e Neoregelia, que não são exclusivos da Mata Atlântica, porém apresentam neste domínio seus centros de diversidade. Os números aqui obtidos corroboram a costa leste do Brasil como um dos principais centros de diversidade e de endemismo de Bromeliaceae (Smith 1955).

O levantamento permitiu avaliar também as condições das coleções de Bromeliaceae depositadas nos herbários no tocante à identificação científica. Tomando por base os cerca de 22.000 espécimes incluídos na base de dados, foram encontrados inicialmente 1.415 nomes, demonstrando que grande parte das coleções da família encontra-se com as identificações desatualizadas. Tal fato pode ser explicado pelas mudanças nomenclaturais (especialmente combinações novas), descrição de novos táxons e sinonimizações constantes que vem sendo publicadas após as monografias de Smith \& Downs (1974, 1977, 1979). Dos 953 táxons registrados no presente levantamento, cerca de 350 foram transferidos de gêneros ou descritos após a elaboração destas obras. Também podemos constatar que alguns gêneros (e.g. Aechmea, Cryptanthus, Neoregelia, Billbergia, Hohenbergia e Dyckia) possuem um grande número de espécimes indeterminados ou com identificações imprecisas, merecendo revisão urgente.

Os estados do Rio de Janeiro, São Paulo e Espírito Santo são os que possuem maior número de espécimes da família depositados 
em herbários, com cerca de 7.500, 3.090 e 2.700 , respectivamente. Da mesma forma, é na Região Sudeste onde estão os acervos com maior número de exsicatas de Bromeliaceae (RB, R, HB e SP, respectivamente). Ainda no tocante às coleções depositadas nos herbários, pôde-se constatar que muitos dos espécimes (inclusive typus) estão sendo perdidos devido à má conservação dos acervos brasileiros. Esta situação merece uma atenção especial, pois sem espécimes bem preservados é impossível realizar trabalhos taxonômicos que possam auxiliar na conservação (Lewinsohn \& Prado 2002). Assim, sugere-se que instituições públicas recebam recursos específicos para manutenção de seus acervos, permitindo assim a preservação dos espécimes em longo prazo. Adicionalmente, políticas de incremento dos herbários através de novas coletas deveriam ser incentivadas, visto que existe uma deficiência de exemplares preservados, o que compromete o avanço do conhecimento do grupo e da diversidade brasileira. Da mesma forma, coleções de espécimes vivos deveriam ser mantidas nas instituições públicas que têm como missão promover o conhecimento e a conservação da biodiversidade brasileira.

Apesar de serem alvos constantes de críticas, as Listas Oficiais de Espécies Ameaçadas são importantes ferramentas para ações conservacionistas, seja por parte do Poder Público (e.g. estabelecimento de UCs, direcionamento de recursos e fiscalização), seja por parte do meio acadêmico, que vem somando esforços para ampliar o conhecimento sobre os táxons (Mendonça \& Lins 2000; Fraga et al. 2007). Dentre os 953 táxons específicos e infraespecíficos registrados no presente levantamento, 338 encontram-se citados em alguma das listas oficias de espécies ameaçadas e apenas 26 possuem categorias distintas dependendo da escala (estadual x nacional) (Tab. 1). Este fato nos leva a crer que, mesmo com metodologias muitas vezes distintas e tendo sido elaboradas em momentos históricos diferentes, as listas são coerentes entre si.
Segundo as listas oficiais, 54 espécies estão incluídas na categoria Criticamente em Perigo (CR), 89 Em Perigo (EP), 182 Vulneráveis (VU) e 17 Raras (R) (Tab. 1). Além destas, três espécies foram indicadas na Revisão da Lista Brasileira (Workshop Biodiversitas 2005) como Extintas na Natureza: Cryptanthus fosterianus, Neoregelia binotii e Nidularium utriculosum. Assim, dentre as espécies de Bromeliaceae registradas na Mata Atlântica cerca de $40 \%$ encontram-se sob alguma categoria de ameaça (existem espécies enquadradas em mais de uma categoria). Mais além, é provável que este número esteja subestimado devido ao pouco conhecimento do real estado de conservação das populações em ambientes naturais, bem como pelo número reduzido de espécimes depositados nos herbários, que compromete a avaliação da distribuição geográfica dos táxons.

Esta situação pode ser ilustrada pelos 218 táxons que foram registrados na Mata Atlântica apenas pela coleção-tipo (Tabs. 1 e 2). Deste conjunto, é importante ressaltar que mais de 180 foram descritos nos últimos 30 anos, e apenas 20 há mais de 50 anos. Quando considerada a procedência destes táxons destacam-se os estados do Espírito Santo (região serrana e Vitória), Bahia (Mata higrófila sul-bahiana) e Rio de Janeiro (Serras dos Órgãos e do Desengano e região sul do estado, entre Angra dos Reis e Parati) com 49, 41 e 46 casos, respectivamente. É também representativo o número de táxons cuja procedência é apenas suposta para a Mata Atlântica (38 táxons), uma vez que nem a etiqueta do material nem o protólogo informam a localidade da coleta. Os números parecem indicar também o avanço no conhecimento taxonômico em gêneros como Canistrum, Canistropsis, Nidularium e Lymania, que foram alvo de recentes revisões (Leme 1997, 1998, 2000, Sousa 2004b). Por outro lado, gêneros de maior riqueza como Vriesea, Aechmea, Cryptanthus, Neoregelia, Tillandsia e Orthophytum necessitam de um grande esforço de coleta, ainda que alguns de 
seus subgêneros ou grupos de espécies tenham sido revistos (Costa 2002; Sousa 2004a; Faria 2006).

Considerando a distribuição geográfica das espécies pelas Unidades Federativas, é notável a partir do nordeste brasileiro o aumento da riqueza entre a Bahia e São Paulo, e o decréscimo a partir do Paraná, em direção ao sul, ainda que não tão evidente quando comparado à primeira região (Fig. 1). Os estados da Região Sudeste e o sul da Bahia abrigam mais da metade das espécies inventariadas (407 spp., 50,7\%), ficando evidente que esta região é o principal centro de diversidade e endemismo da família no domínio. Na Região Nordeste fica evidente o Centro Pernambucano, onde dos 93 táxons registrados, 45,5\% são endêmicos (SiqueiraFilho et al. 2006).

Alguns gêneros apresentam distribuição predominante em alguns estados, enquanto outros, como Aechmea, Tillandsia e Vriesea, possuem representantes ao longo de todo domínio. Apesar da ampla distribuição, Aechmea apresenta dois importantes centros de diversidade na Mata Atlântica. O primeiro em Pernambuco e Alagoas e outro entre a Bahia e o Rio de Janeiro. Vriesea possui maior diversidade entre a Bahia e Santa Catarina, incluindo Minas Gerais, com destaque para o Rio de Janeiro onde ocorrem 93 espécies. Hohenbergia, Lymania, Portea e Ronnbergia distribuem-se preferencialmente na hiléia baiana, onde ocorrem 21, oito, sete e quatro espécies, respectivamente. Cryptanthus apresenta o maior número de espécies entre a Bahia (10 spp.) e o Espírito Santo (25 spp.), Dyckia no Paraná (15 spp.), Santa Catarina (12 spp.) e Rio Grande do Sul (11 spp.) e Neoregelia no Espírito Santo (38 spp.) e no Rio de Janeiro (46 spp.).

Os corredores de biodiversidade visam manter a integridade da biota regional em grandes unidades da paisagem sujeitas a uma matriz de usos econômicos e conservacionistas (Cavalcanti 2006). Os corredores propostos para a Mata Atlântica (MMA 1998, Fonseca et al. 2004, Ayres et al. 2005) constituem uma importante ferramenta de conservação, considerando o isolamento dos habitats decorrente da crescente e contínua fragmentação dos ambientes naturais e os principais centros de riqueza e endemismos de Bromeliaceae ocorrentes na Mata Atlântica (Martinelli 2006).

Os corredores têm sido abordados sob o ponto de vista da conectividade, onde a relação funcional entre fragmentos permite o contágio espacial entre o habitat e o movimento de organismos em resposta à estrutura da paisagem, possibilitando o fluxo de espécies, sementes e grãos de pólen (Urban \& Shugart 1986, With \& et al. 1997). Sob o enfoque de planejamento regional em áreas prioritárias para conservação, os corredores são unidades que incorporam mosaicos de diferentes paisagens, usos da terra e de áreas protegidas, no intuito de promover a conectividade entre hábitats fragmentados e de proteger e garantir a sobrevivência das espécies e suas populações, num enfoque integrado e de larga escala de conservação, levando em consideração também às demandas sócio-econômicas e a ocupação urbana (Saunders \& Hobb1991; Sanderson et al. 2003; Aguiar et al. 2003; Fonseca et al. 2004; Rocha et al. 2006).

Os três corredores da Mata Atlântica (Central, Serra do Mar e Nordeste) abrigam juntos 671 espécies de Bromeliaceae (Tabs. 1 e 3), o que corresponde a $83,6 \%$ do total de espécies registradas no domínio. O mais rico é o Corredor Central, com 396 espécies (49,3\%), seguido pelo Corredor da Serra do Mar, com 369 (46\%), sendo o Corredor do Nordeste o que apresenta a menor riqueza (86 espécies - 10,7\%). Uma razão para o menor número de espécies no Corredor do Nordeste parece estar relacionada ao alto grau de fragmentação e à perda dos ambientes florestais ao norte do Rio São Francisco (Tabarelli et al. 2006). Por outro lado, a maior riqueza nos outros dois corredores pode em parte ser explicada pelo maior número e extensão de fragmentos florestais. Verificase ainda, para os três corredores, altos 
percentuais relativos de espécies endêmicas da Mata Atlântica (CC - 84,8\%; CSM 83,7\%; CNE - 61,6\%) (Tab. 3).

No tocante ao status de conservação, os três corredores juntos possuem $84,1 \%$ do total de espécies ameaçadas da Mata Atlântica (265 spp.). O Corredor Central (CC) abriga o maior número de espécies ameaçadas (16652,7\%), sendo 149 delas endêmicas da Mata Atlântica. O Corredor da Serra do Mar (CSM), por sua vez, contém $143(45,4 \%)$ espécies ameaçadas, sendo 117 endêmicas. Por fim, o Corredor do Nordeste (CNE) abriga $24(7,6 \%)$ espécies, sendo 14 endêmicas (Tab. 3). Estes resultados demonstram a relevância dos corredores da biodiversidade quanto à riqueza, endemismo e ocorrência de espécies ameaçadas de Bromeliaceae, reforçando a importância do efetivo estabelecimento de estratégias em nível regional para a conservação da família no domínio.
Bromeliaceae é uma das famílias de angiospermas no Brasil que mais possui especialistas e informações disponíveis na literatura. Apesar disto, a avaliação dos números aqui obtidos deve levar em conta a lacuna existente no conhecimento da composição florística de algumas áreas remanescentes dentro do domínio, das quais temos pouco ou nenhum registro de coletas. Da mesma forma, não podemos ignorar que muitos táxons aqui listados possuem circunscrição imprecisa. Assim, a coleta de espécimes georeferenciados e com informações sobre tamanho e estado de conservação das populações, a relização de inventários, principalmente nas Unidades de Conservação, e a revisão de grupos devem ser fomentados e incentivados para que, num fututo próximo, as lacunas sobre a taxonomia, distribuição e conservação das espécies sejam menores.

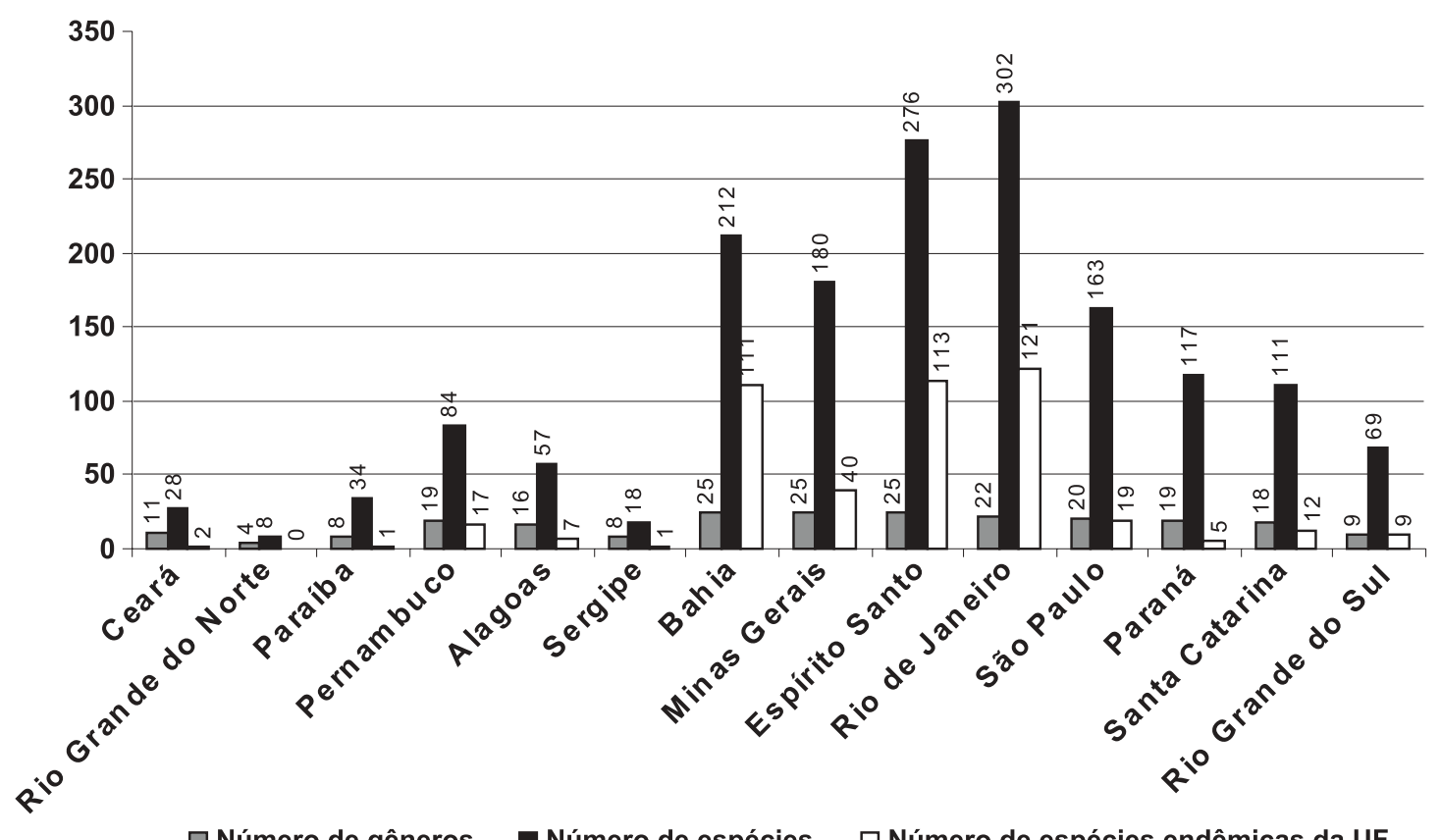

Figura 1 - Número de gêneros, espécies e espécies endêmicas de Bromeliaceae na Mata Atlântica por Unidade Federativa (UF). 


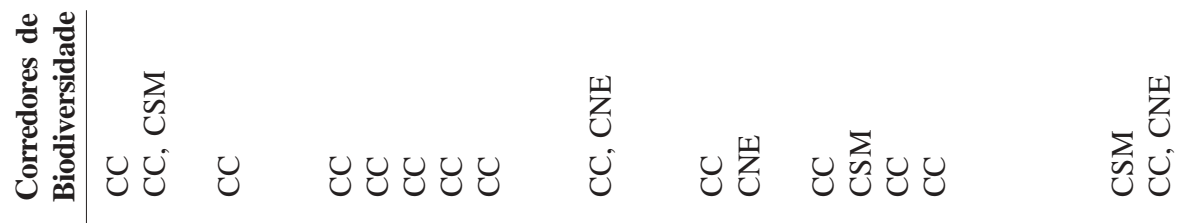

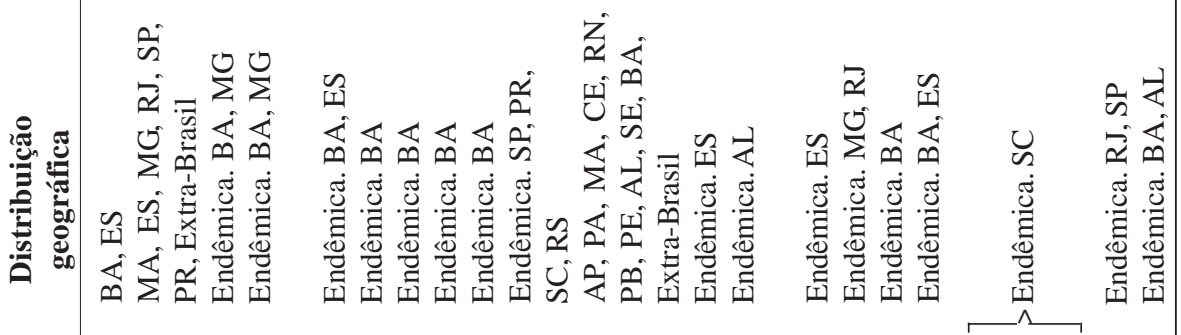

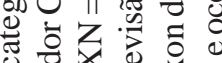

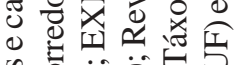

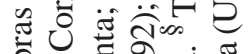
ठ일.

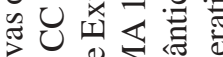

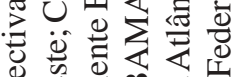

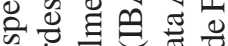

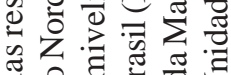
要

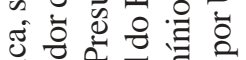

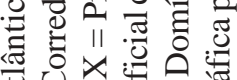

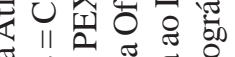

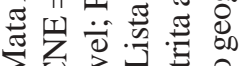

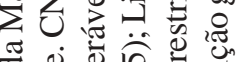

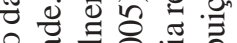

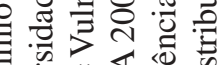
管

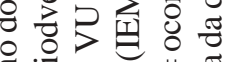
政

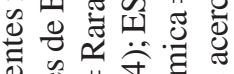

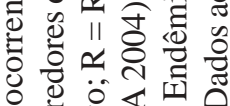

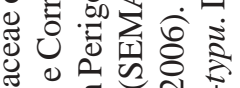

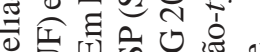

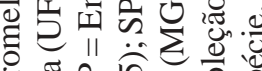

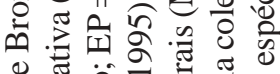

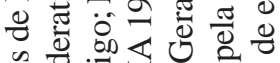

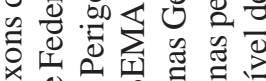

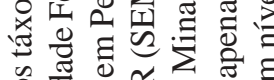
ช。유.

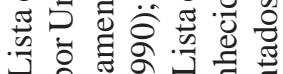

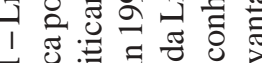
ส

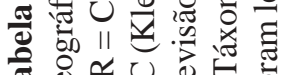

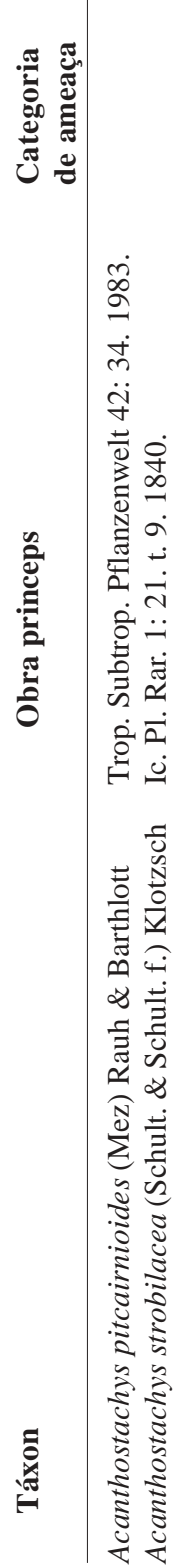

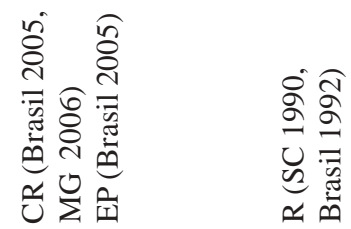

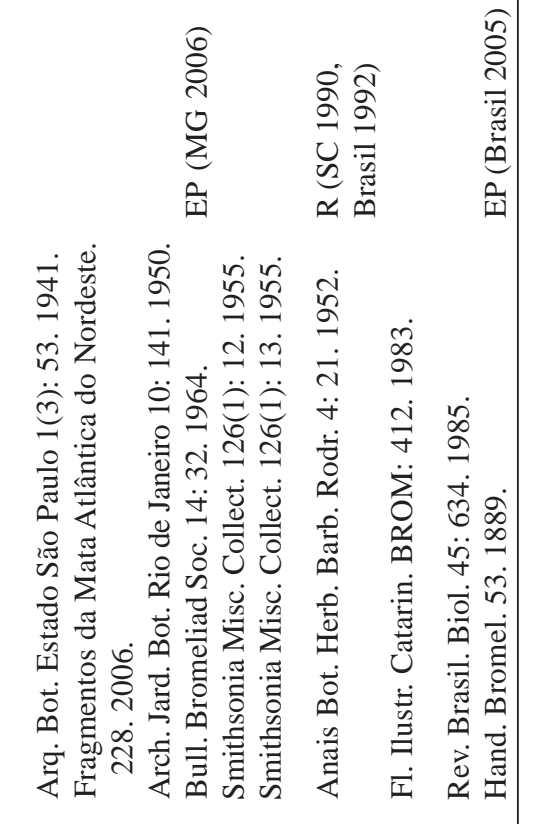

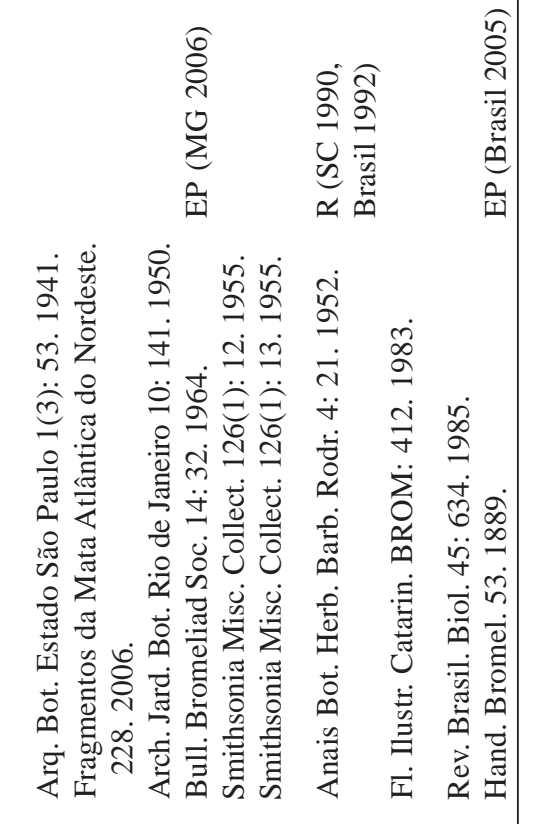

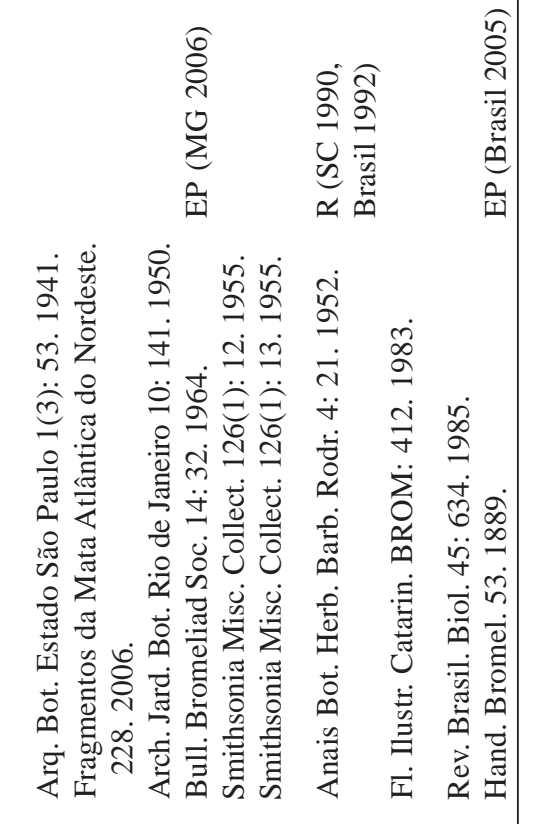

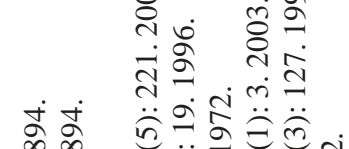
-

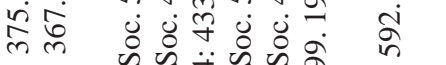

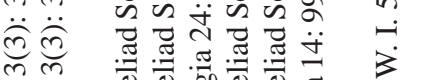

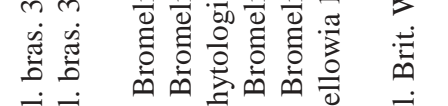

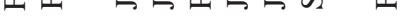

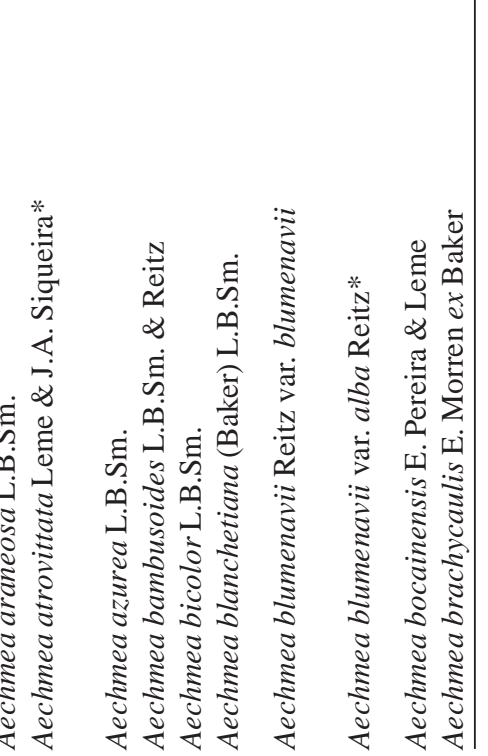




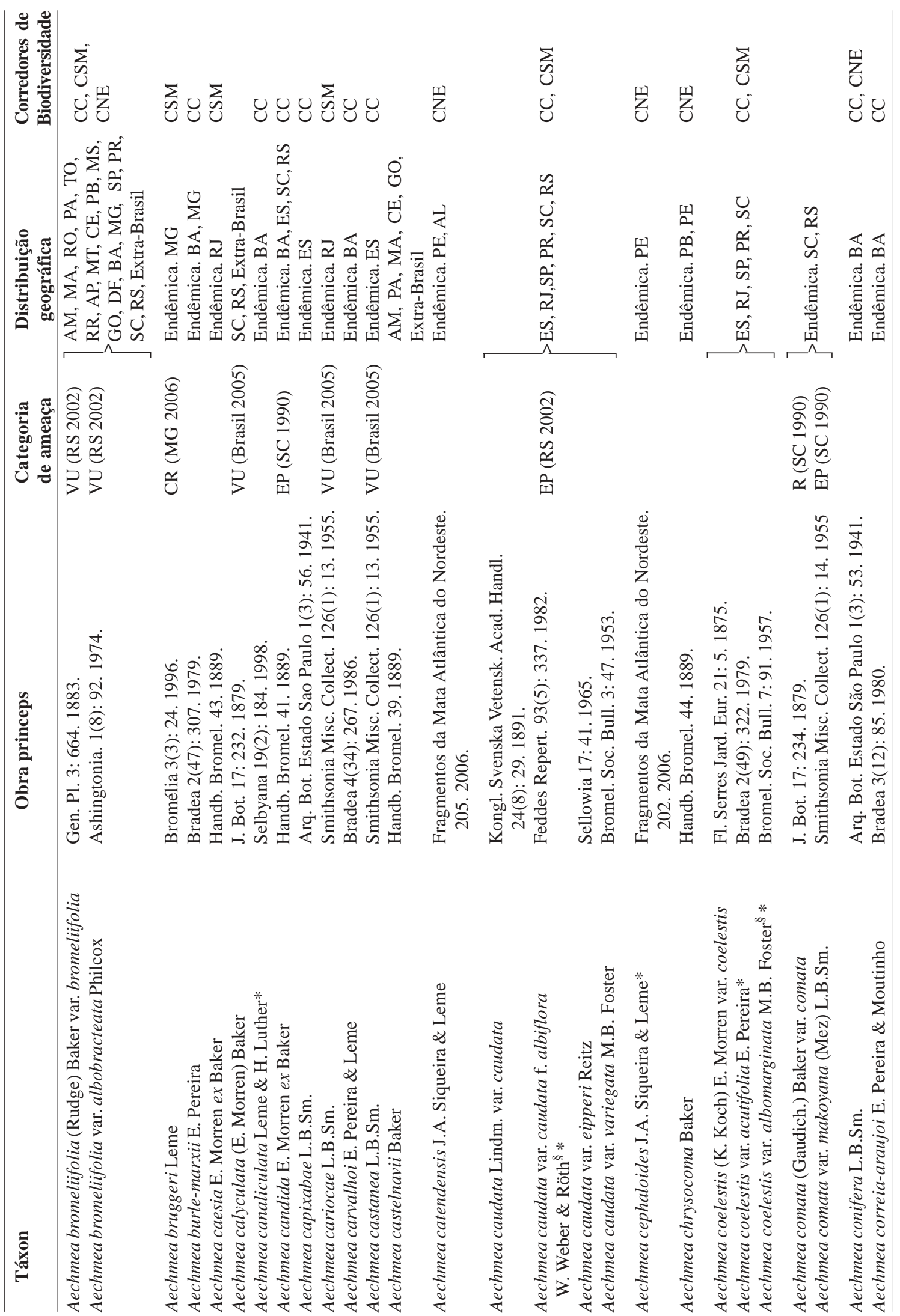

Rodriguésia 59 (1): 209-258. 2008 


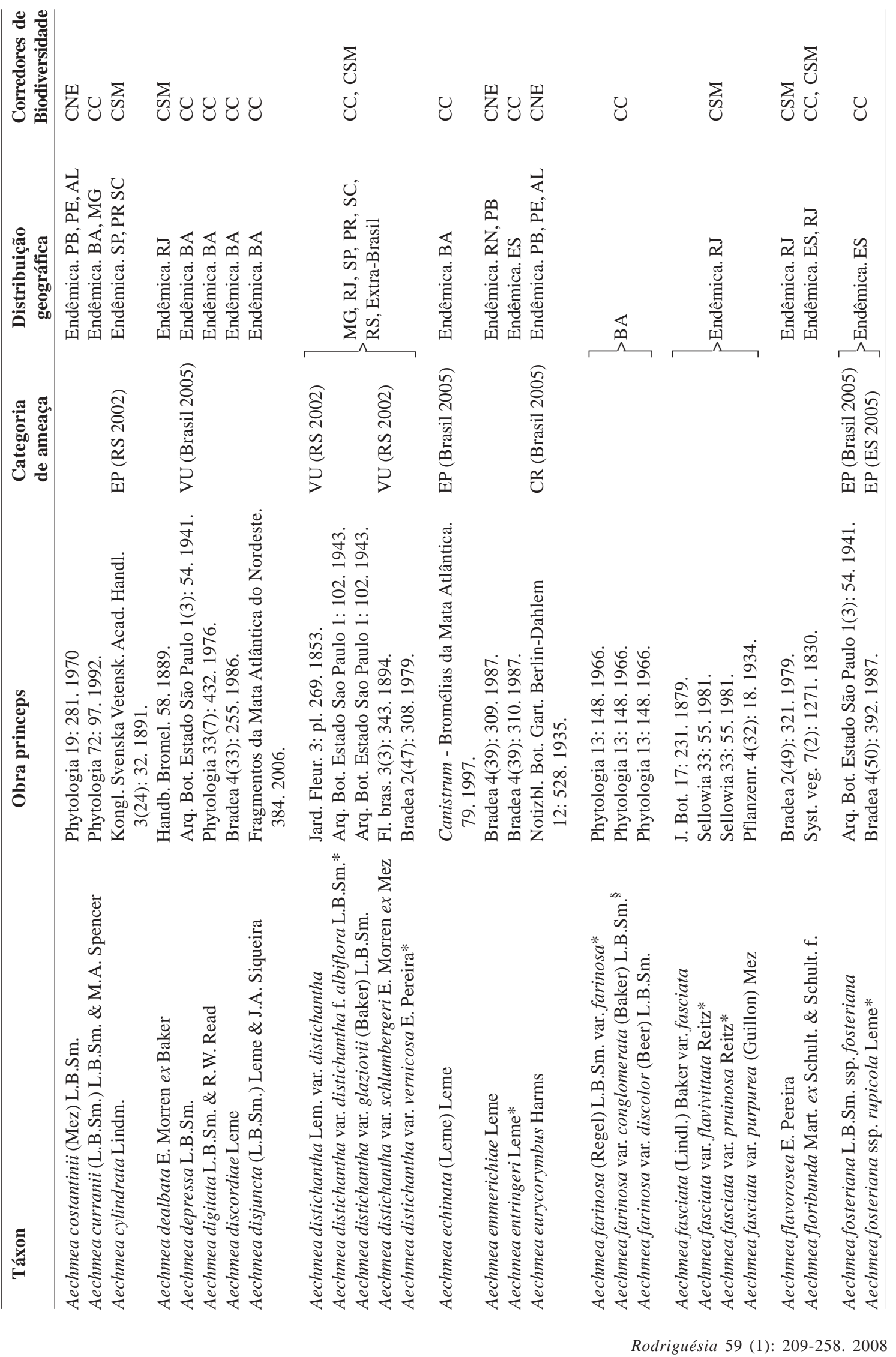




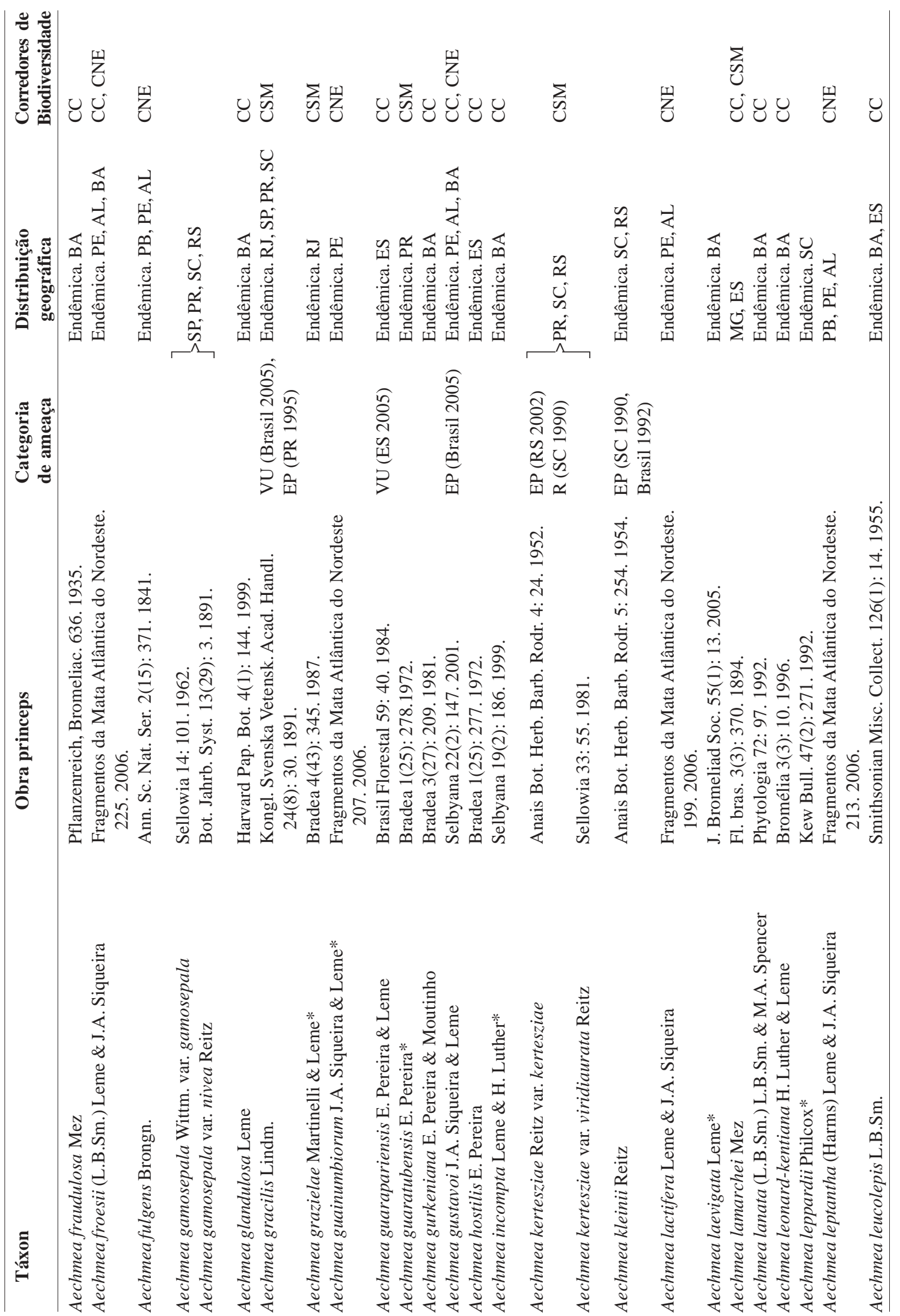

Rodriguésia 59 (1): 209-258. 2008 


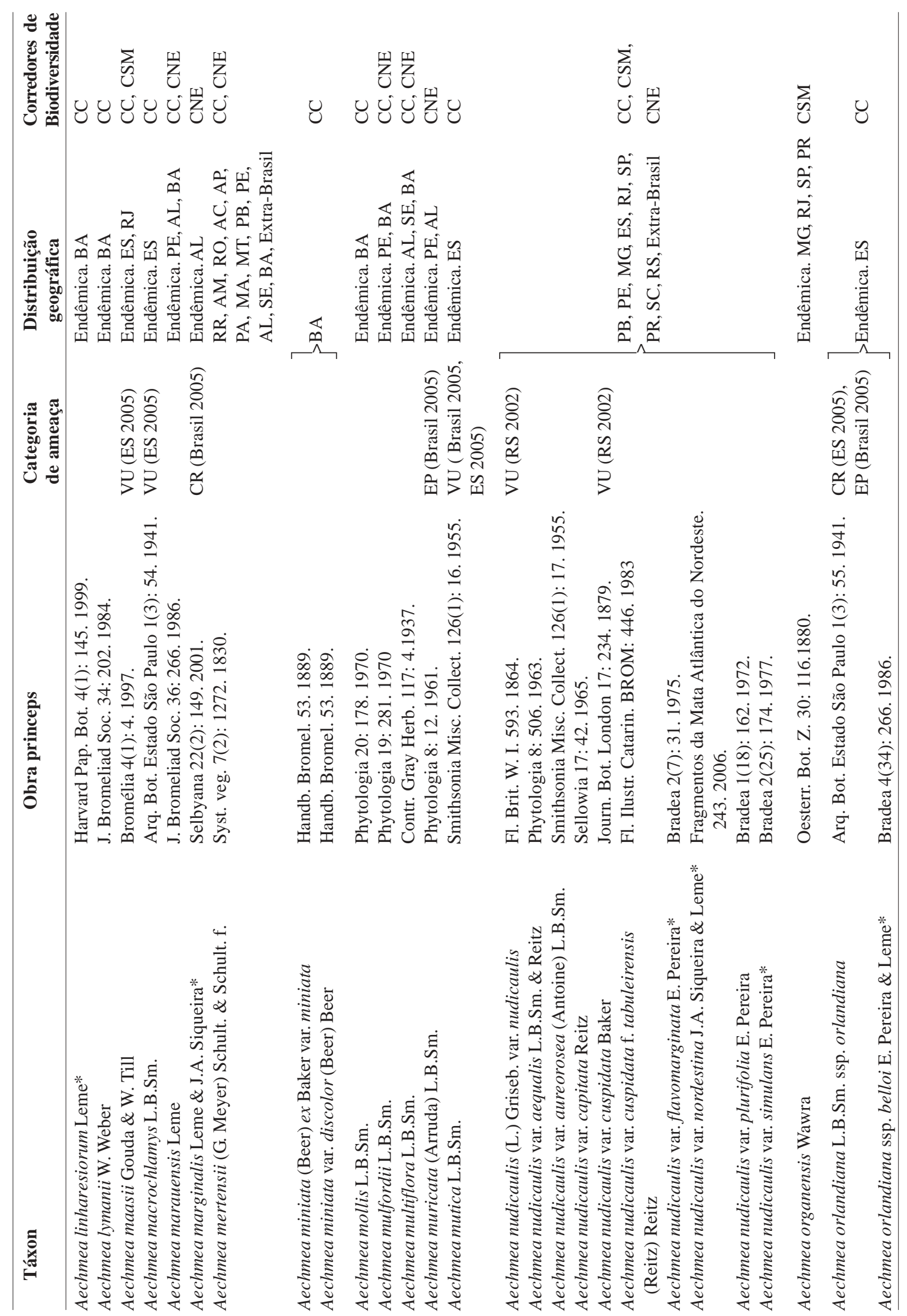




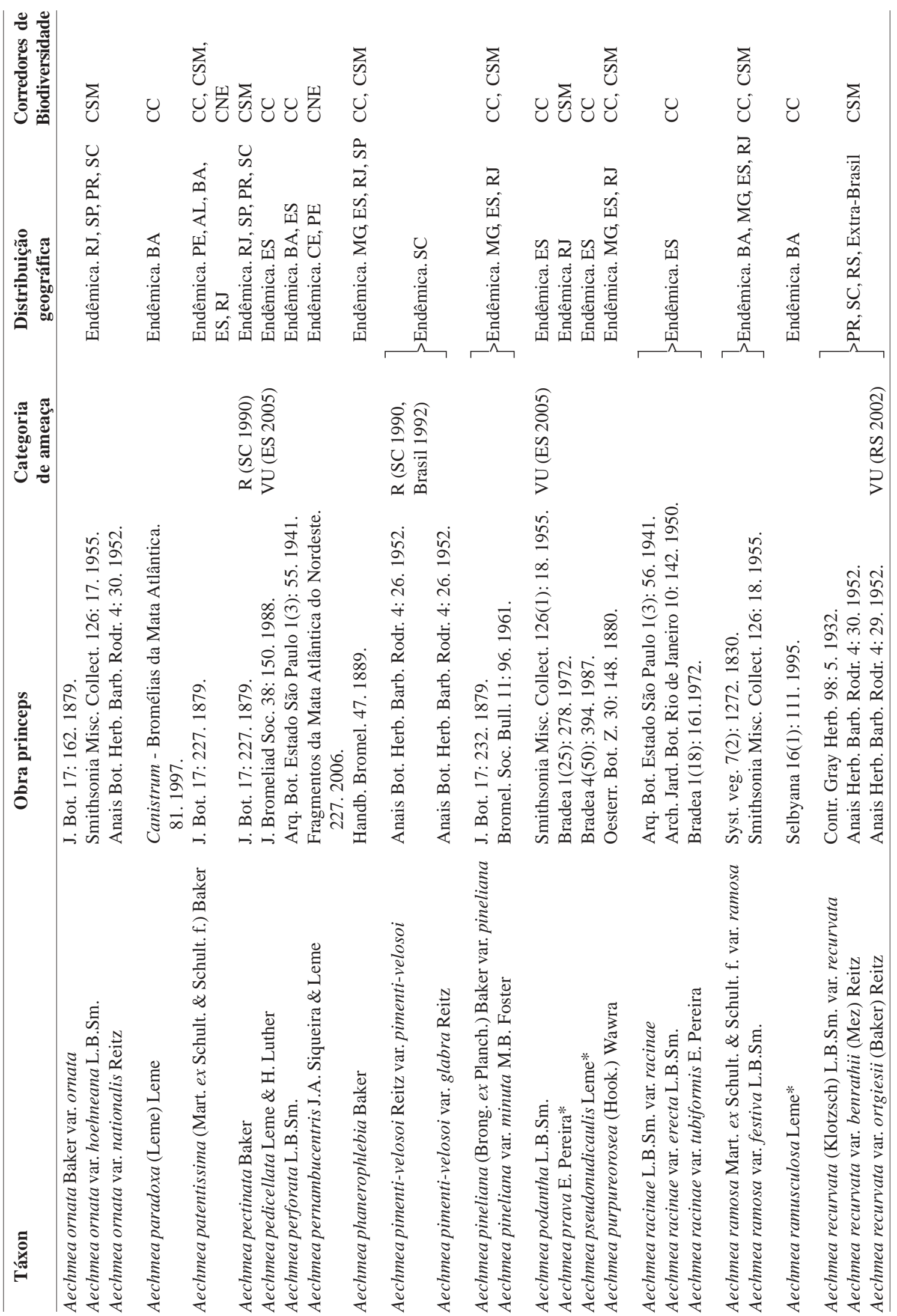

Rodriguésia 59 (1): 209-258. 2008 


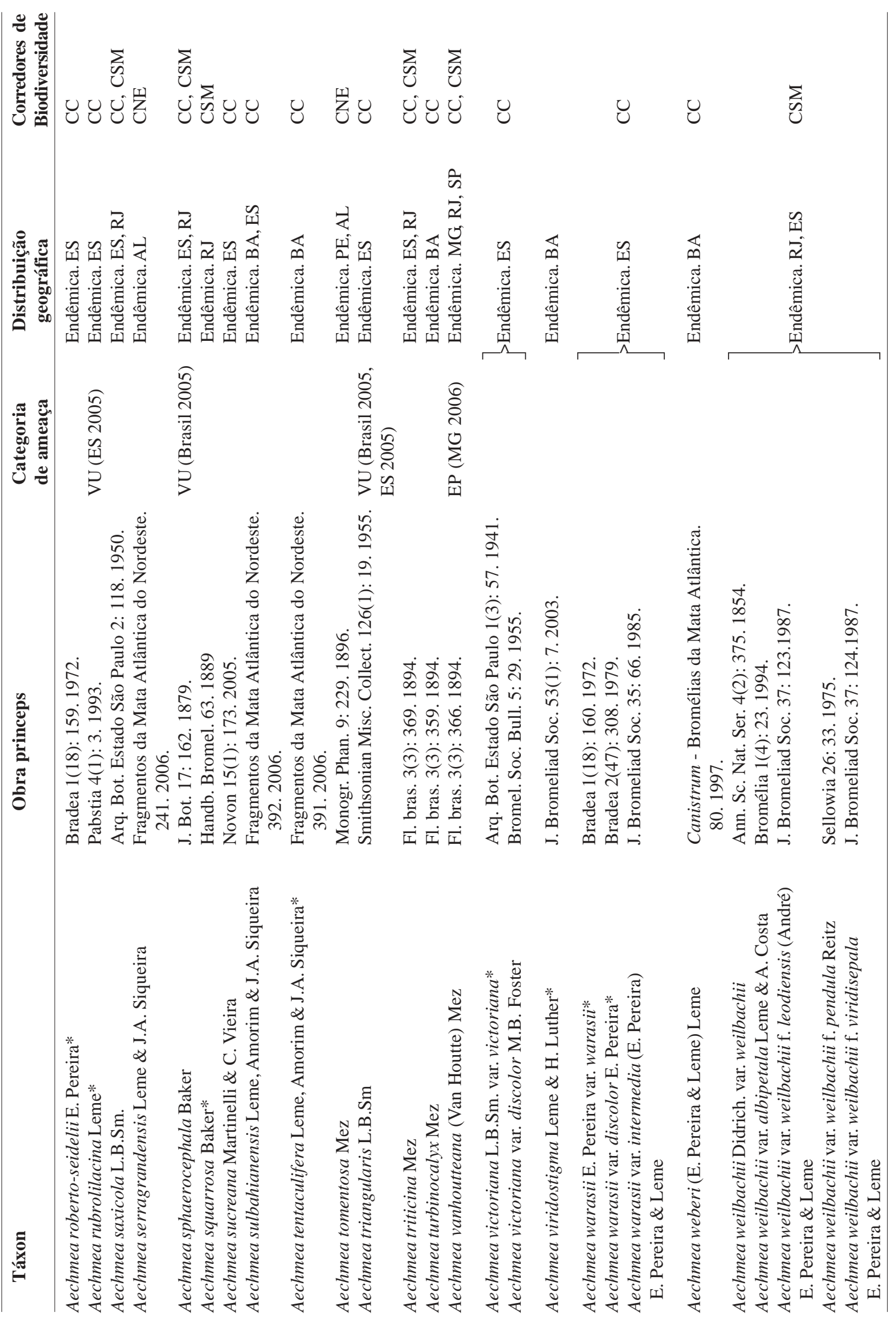




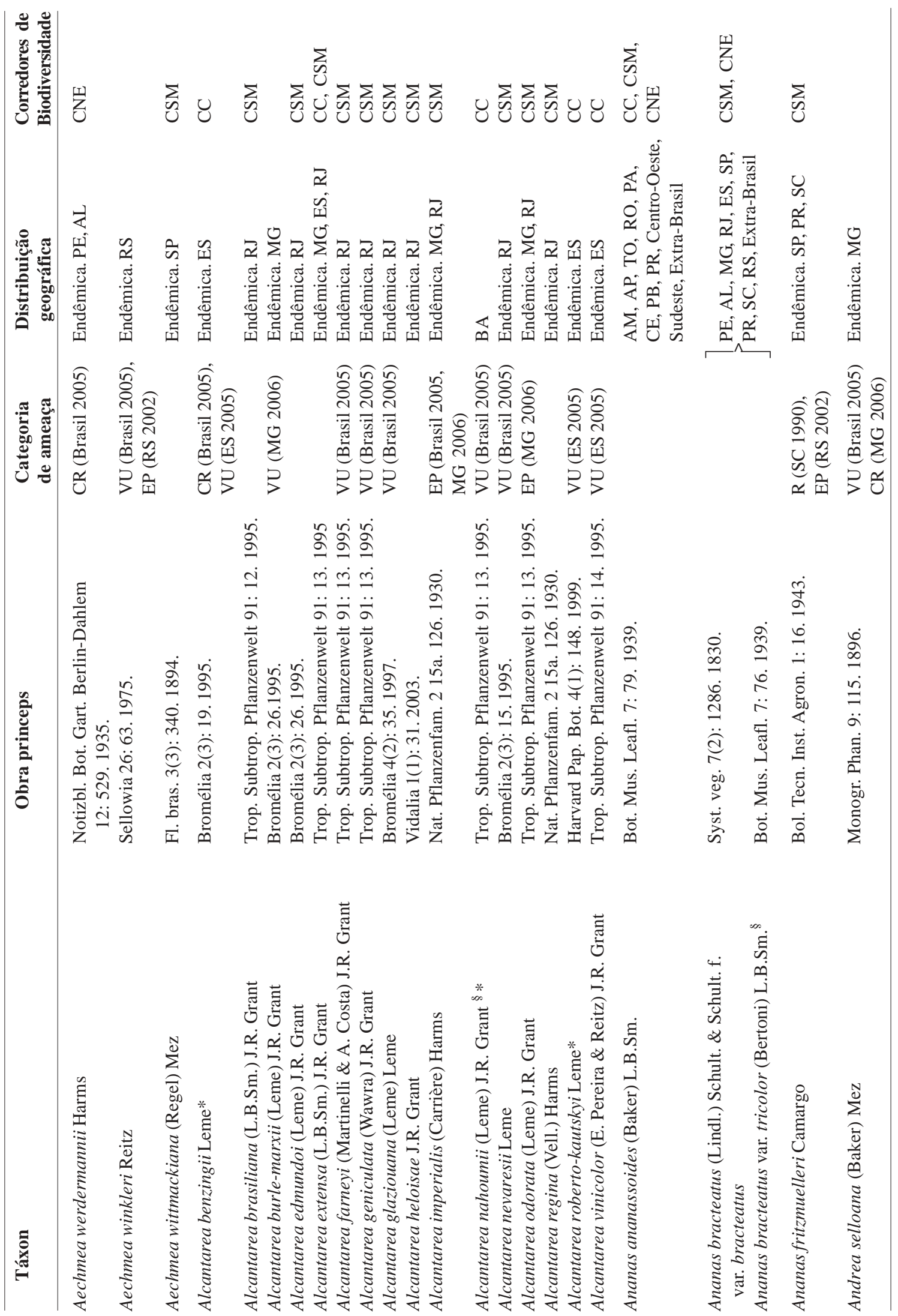




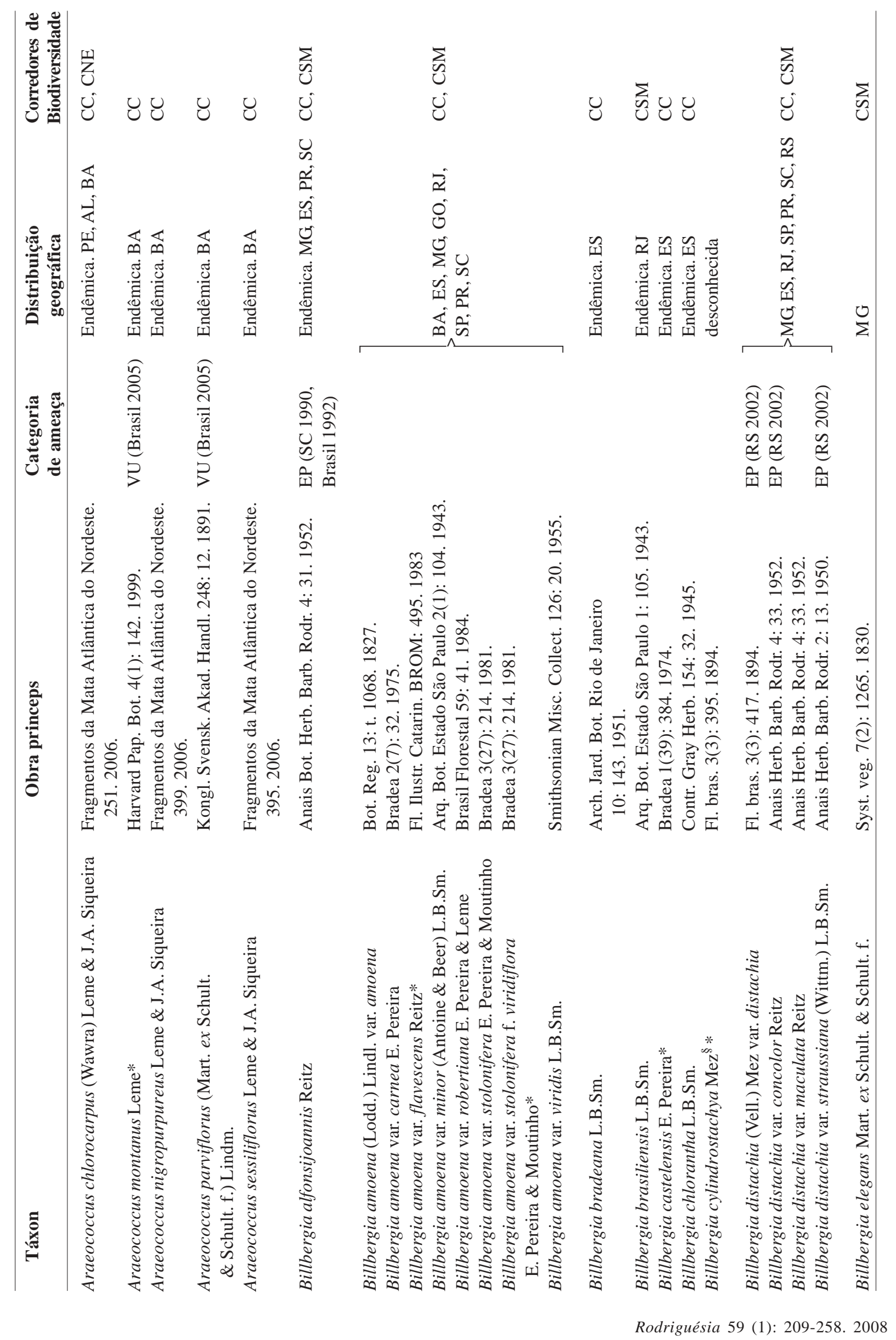




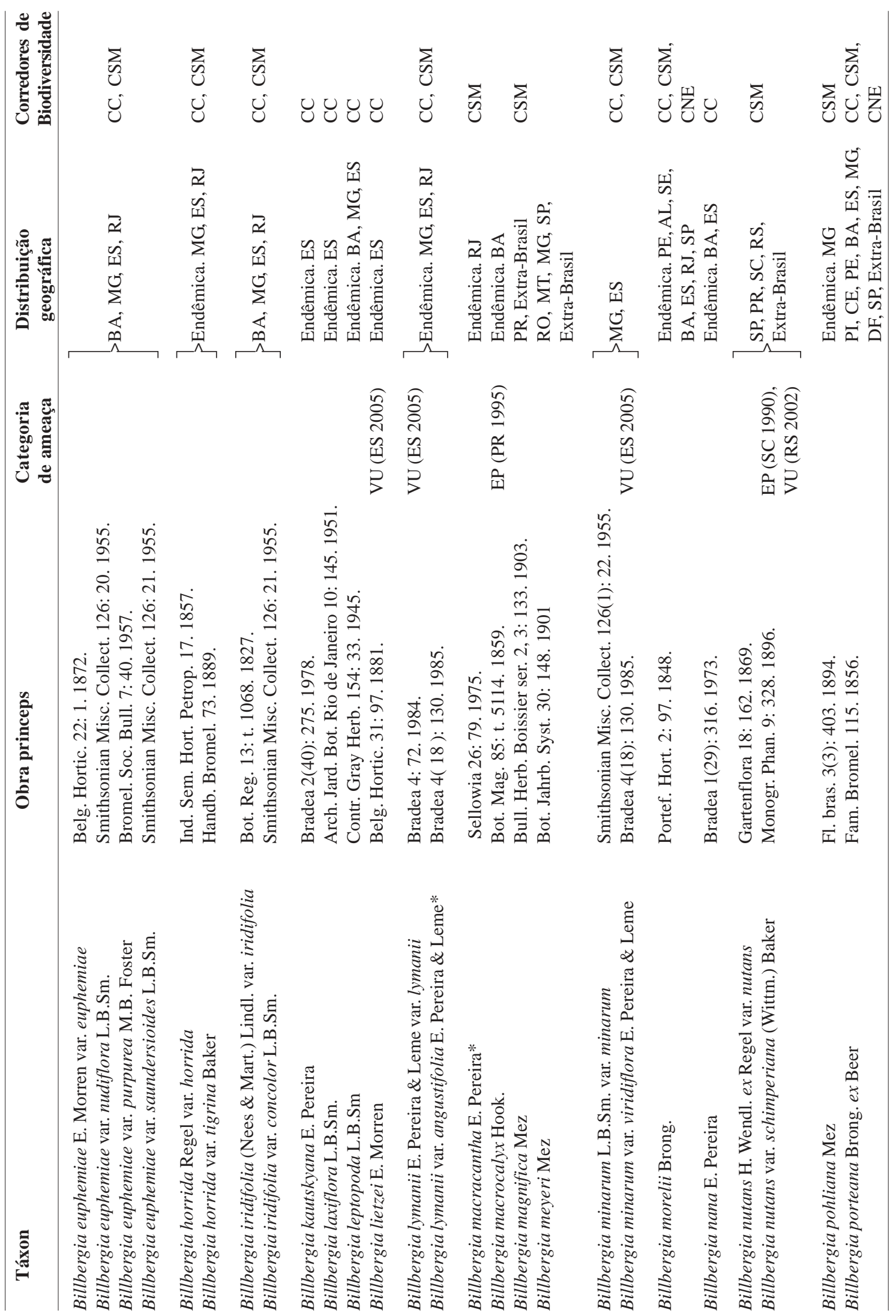

Rodriguésia 59 (1): 209-258. 2008 

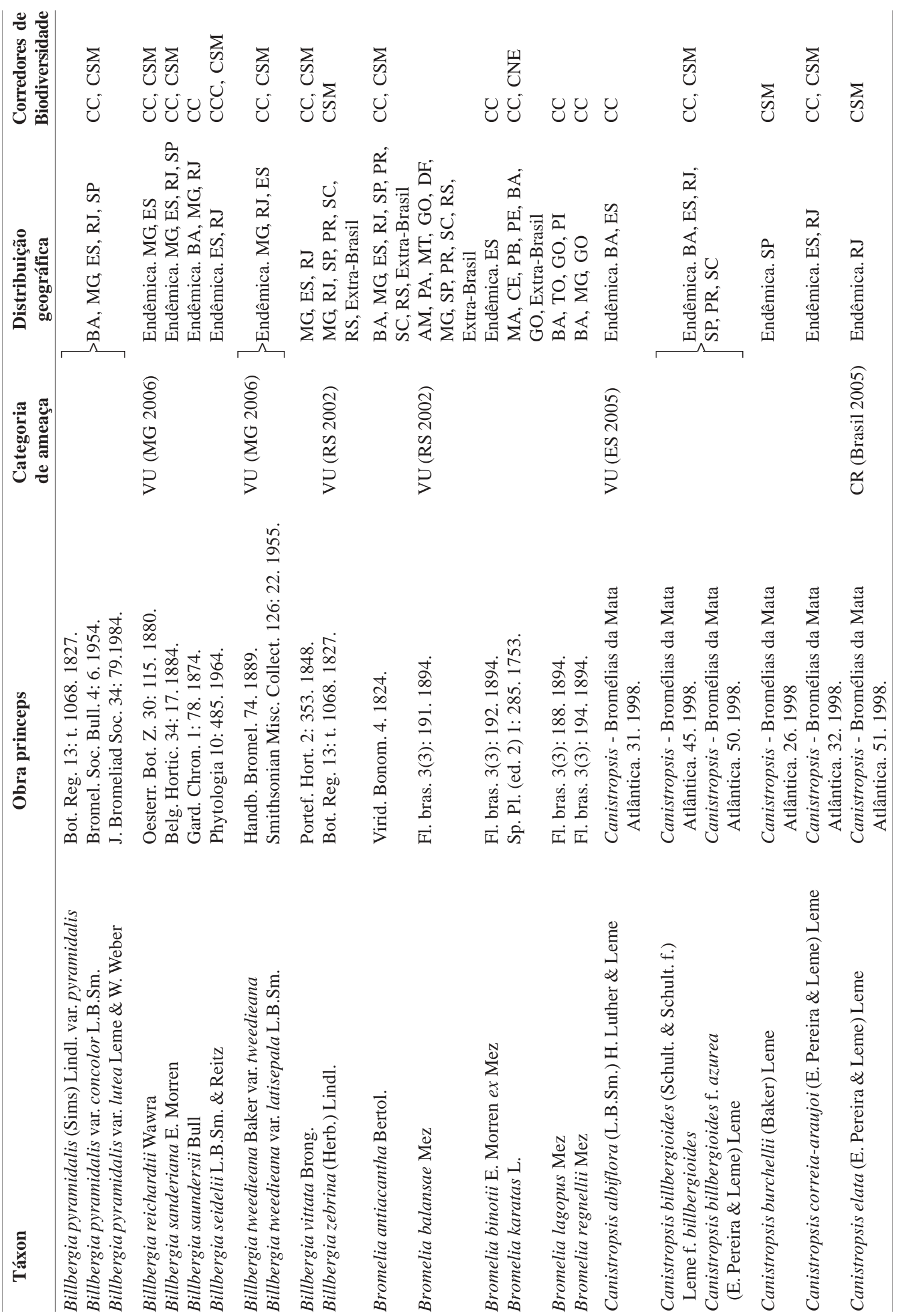

Rodriguésia 59 (1): 209-258. 2008 


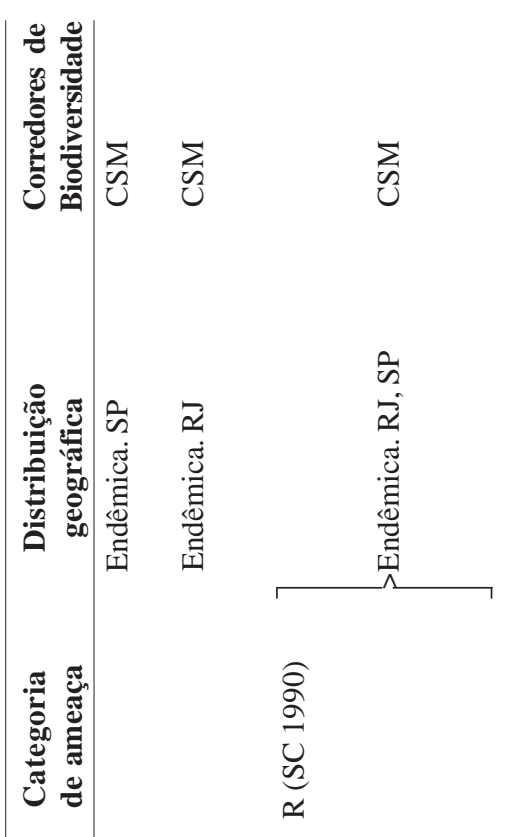

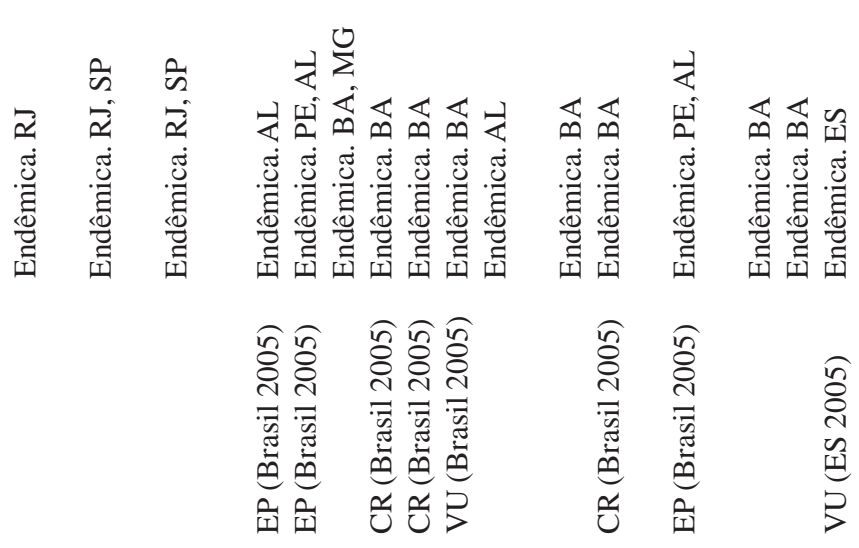

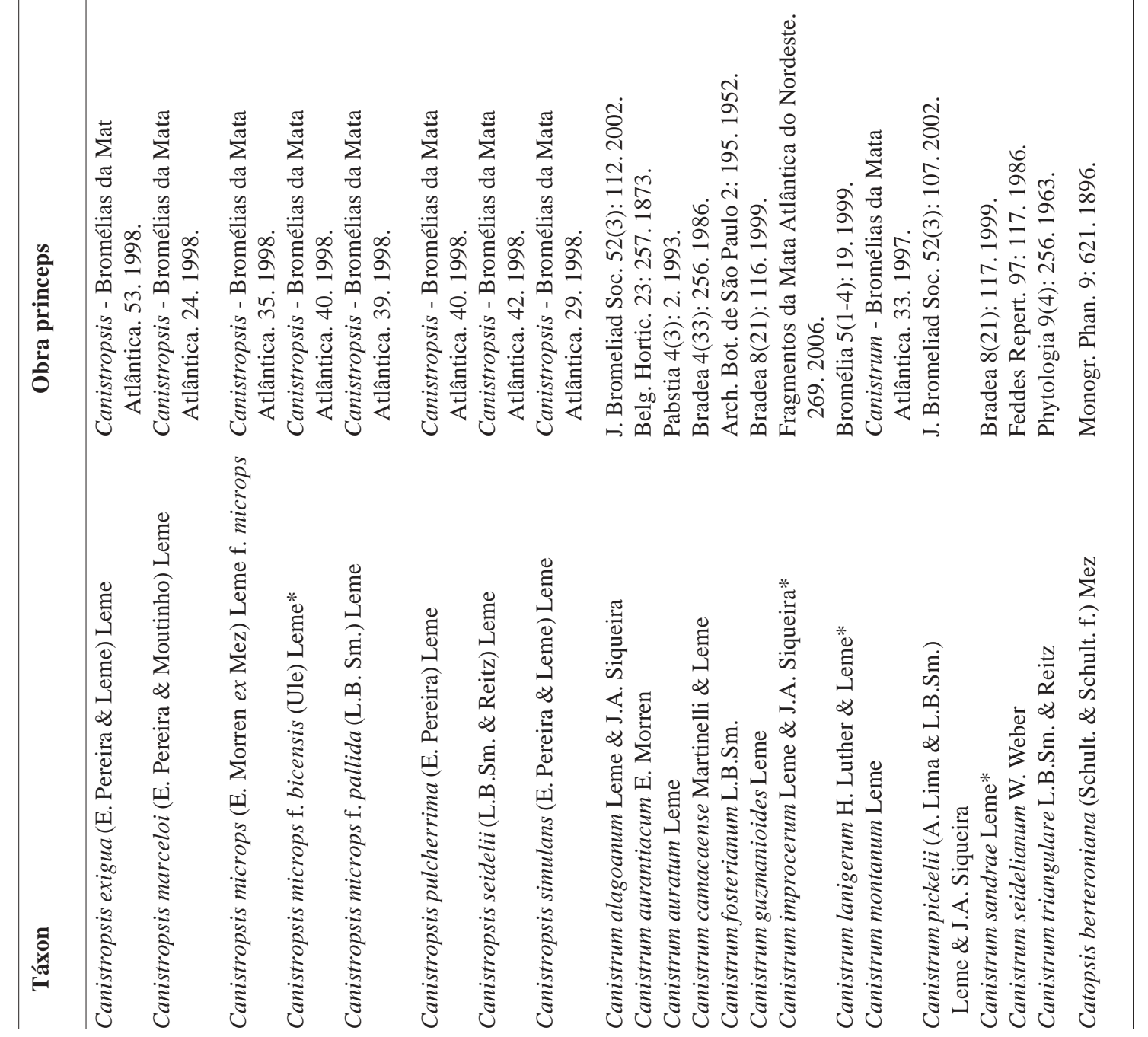

Rodriguésia 59 (1): 209-258. 2008 


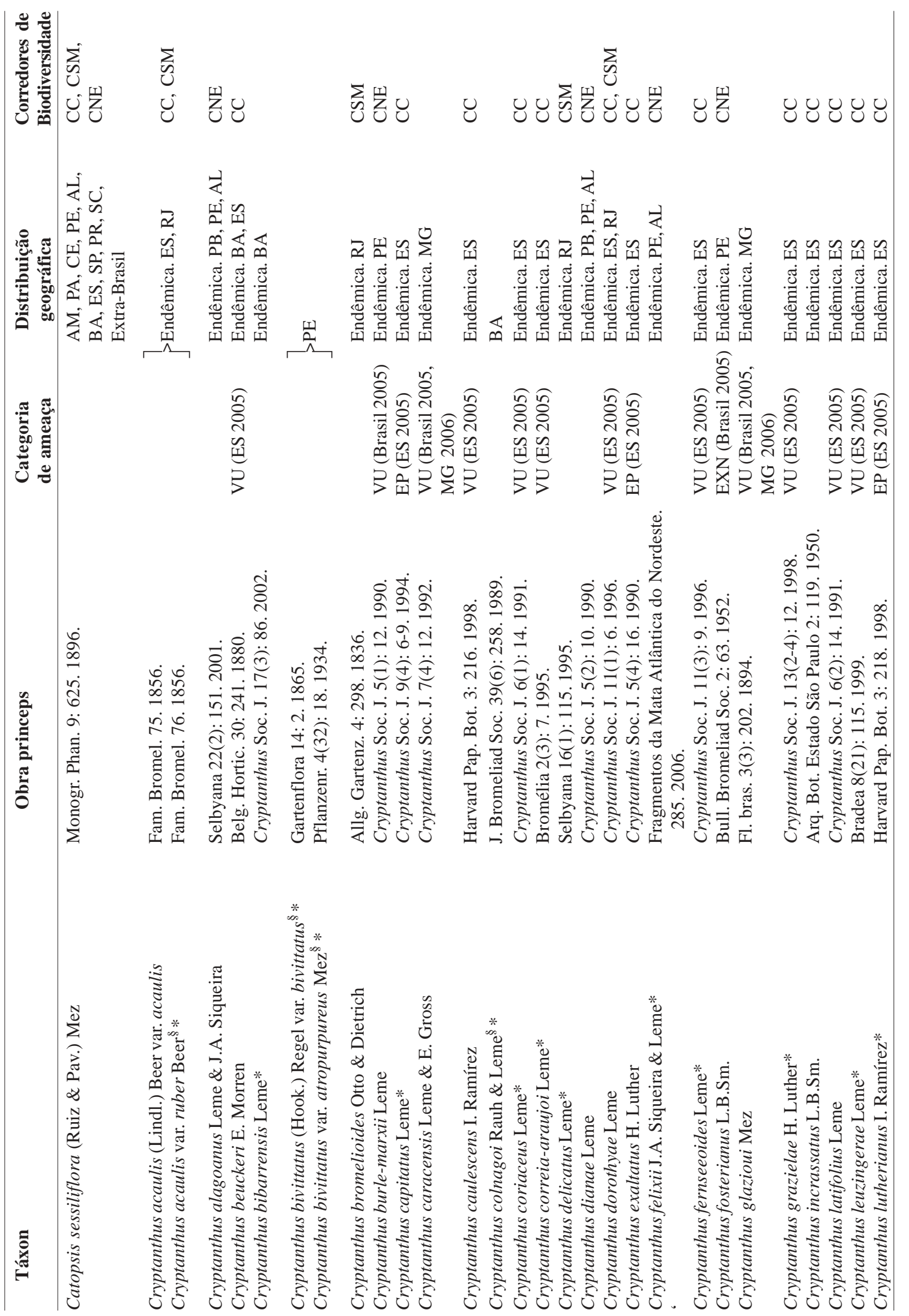




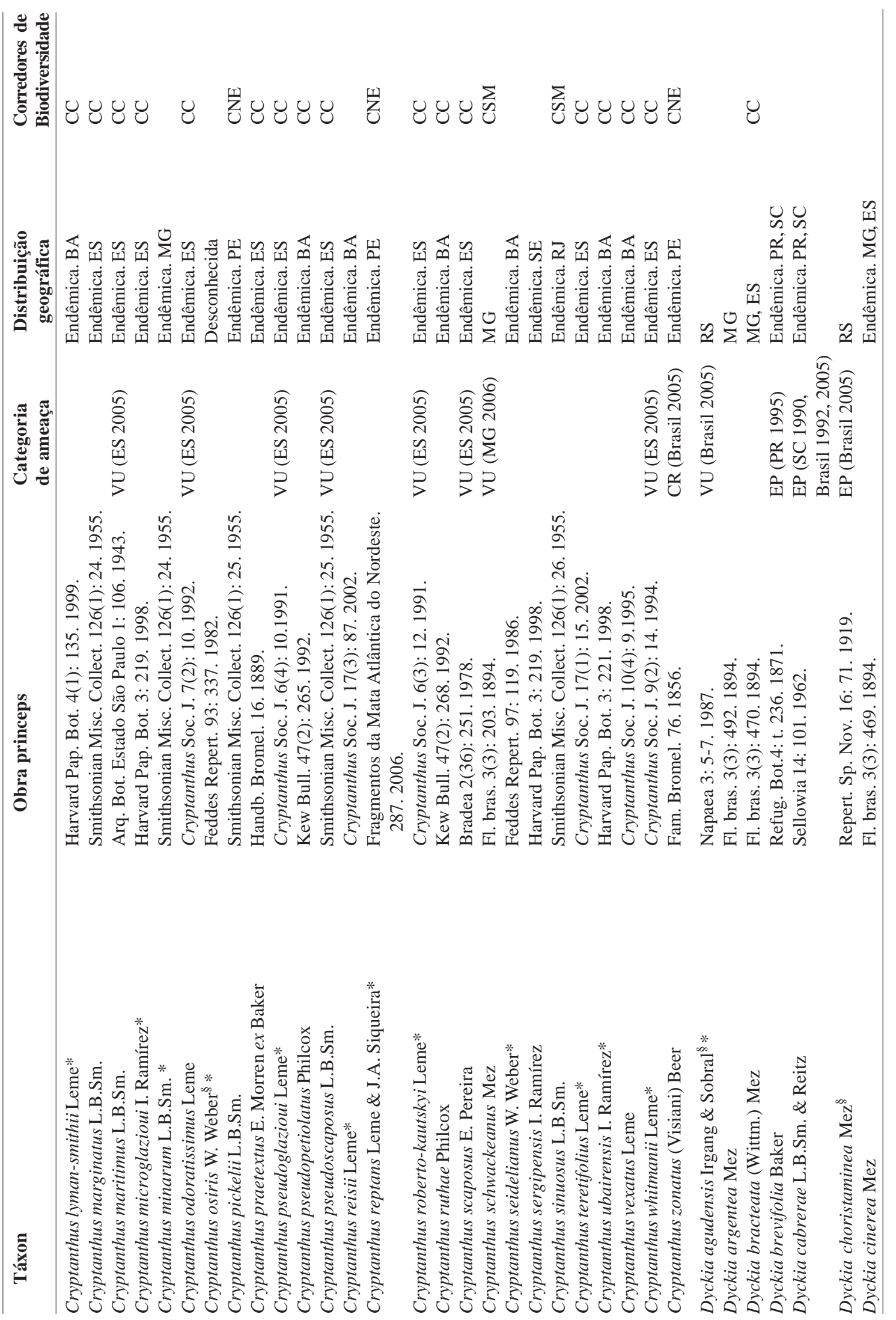

Rodriguésia 59 (1): 209-258. 2008 


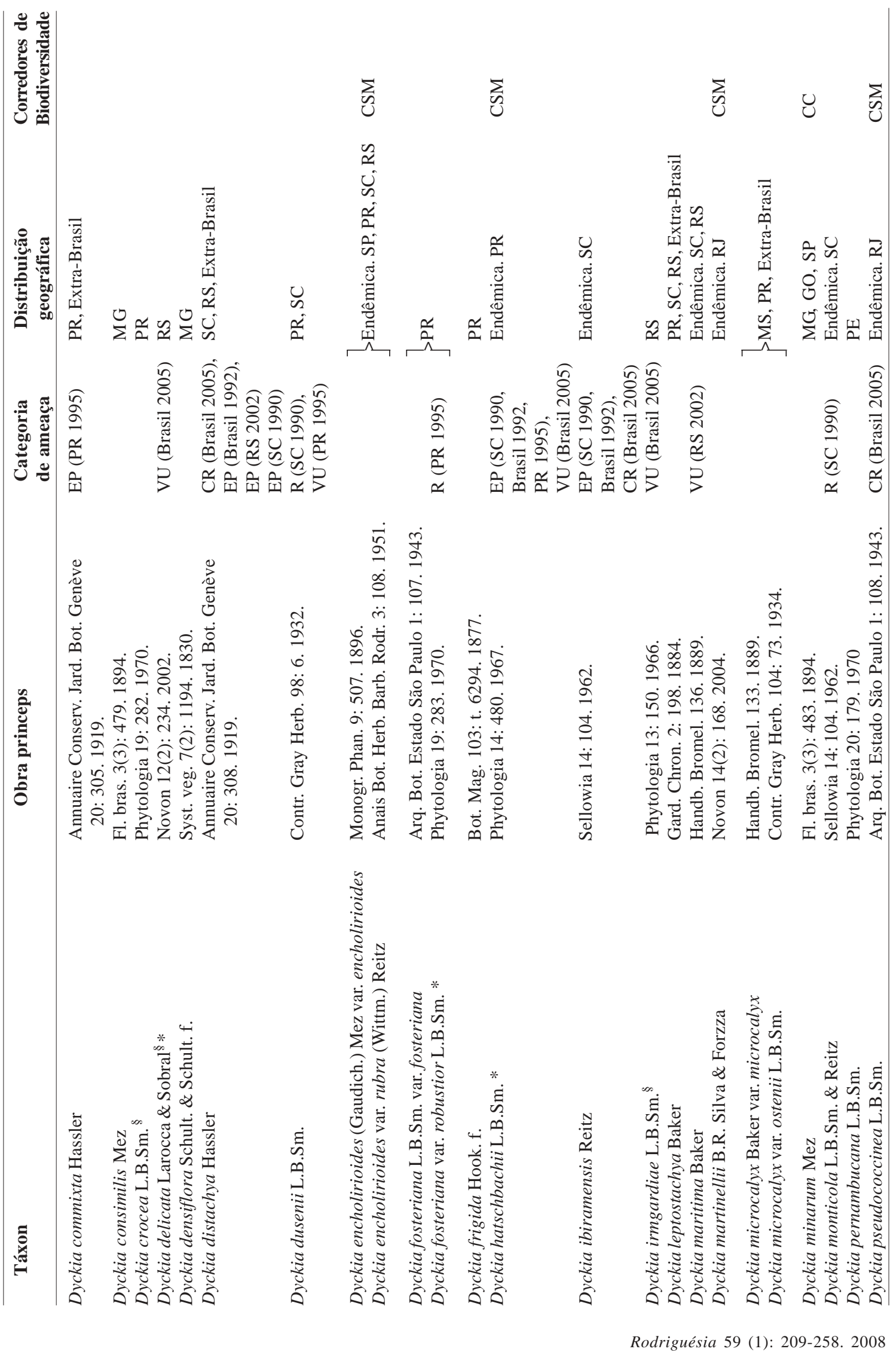




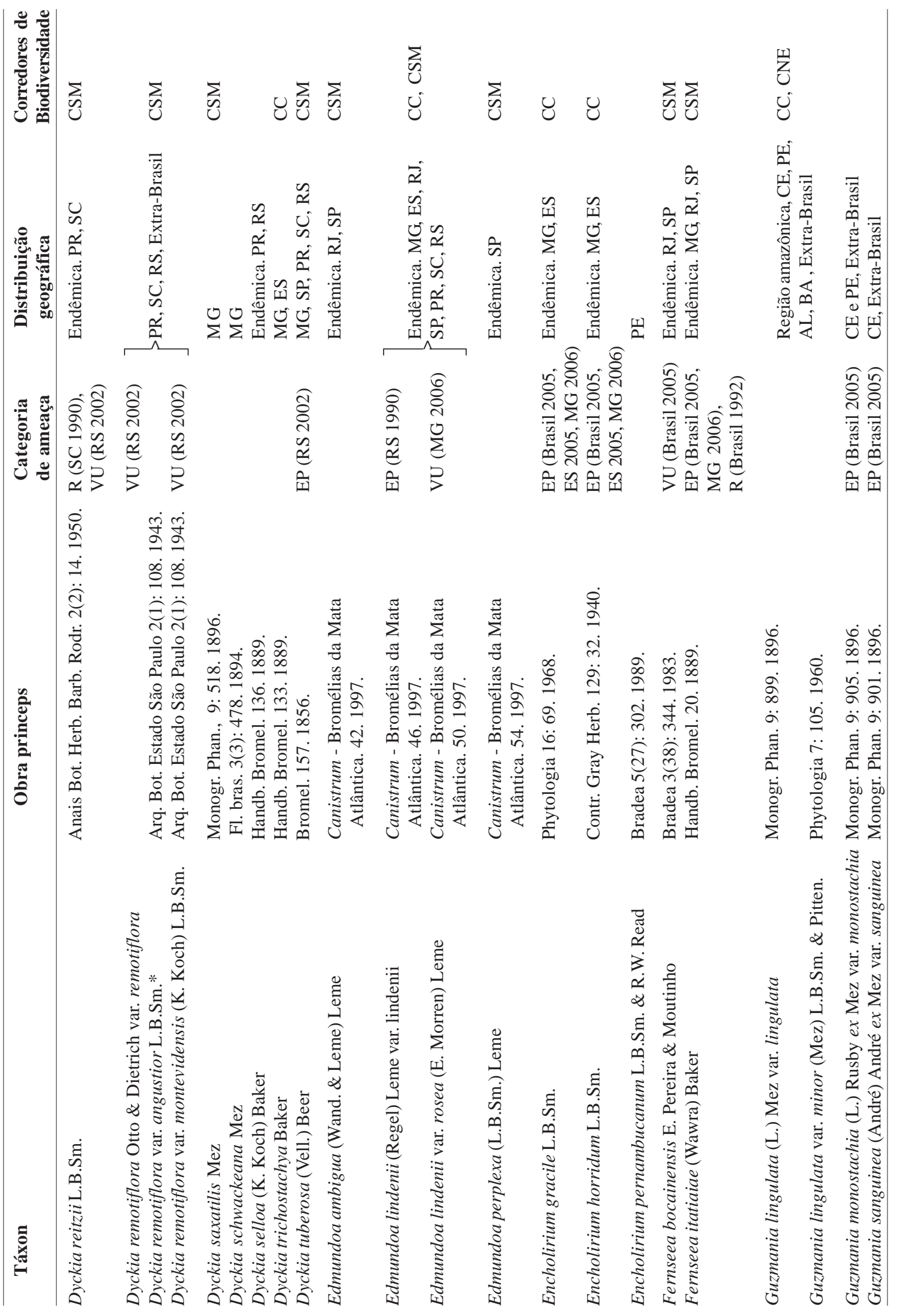

Rodriguésia 59 (1): 209-258. 2008 


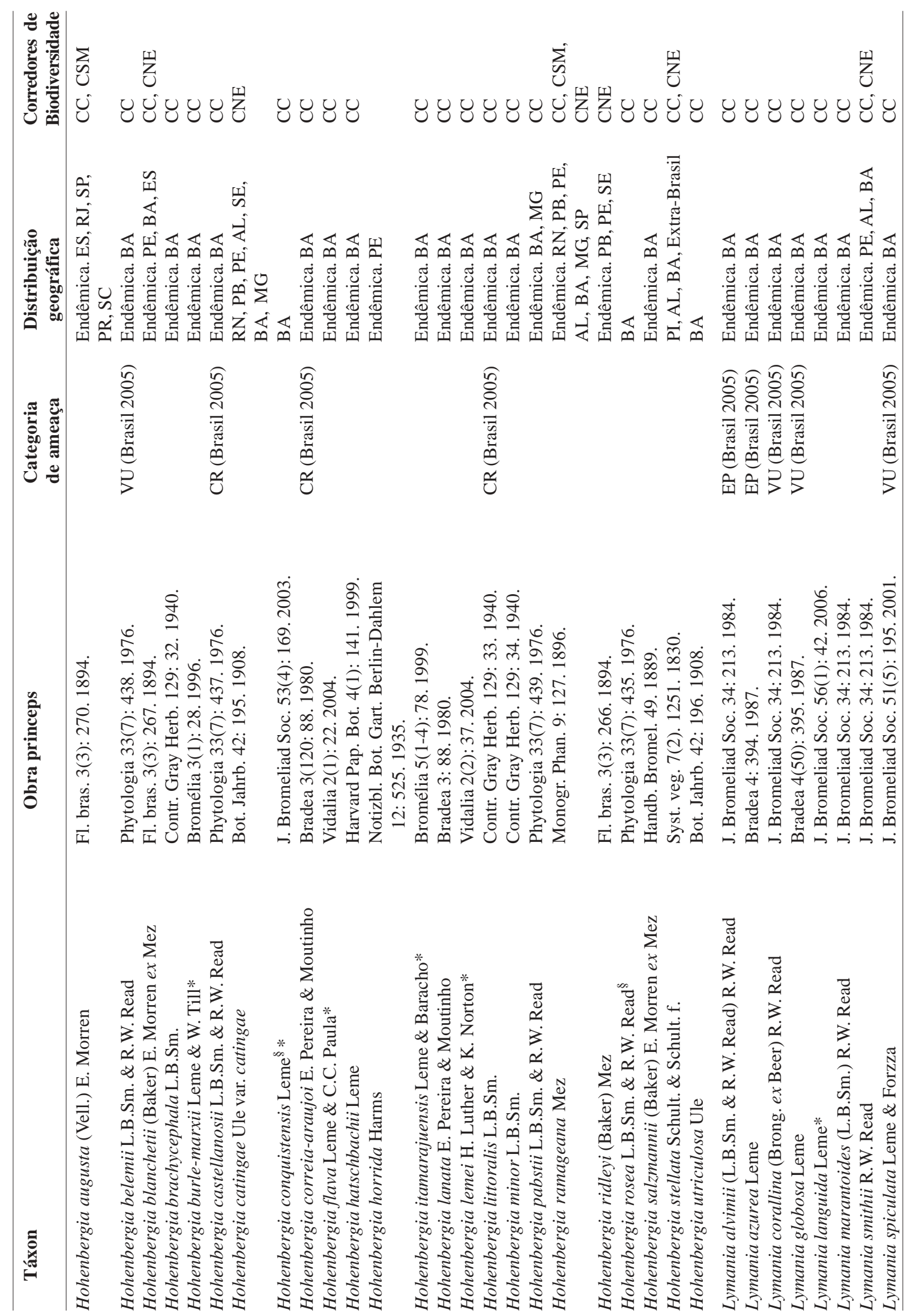




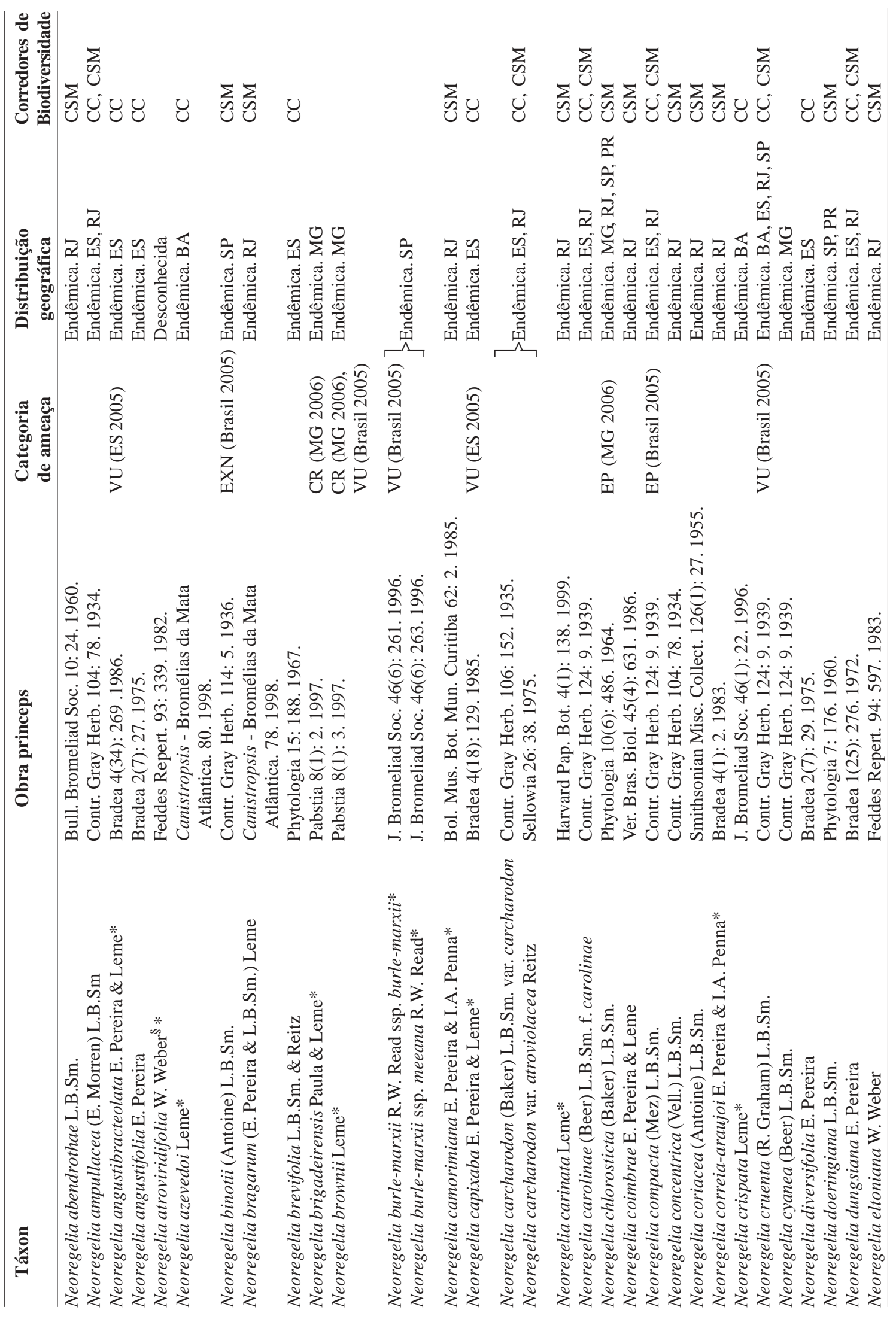




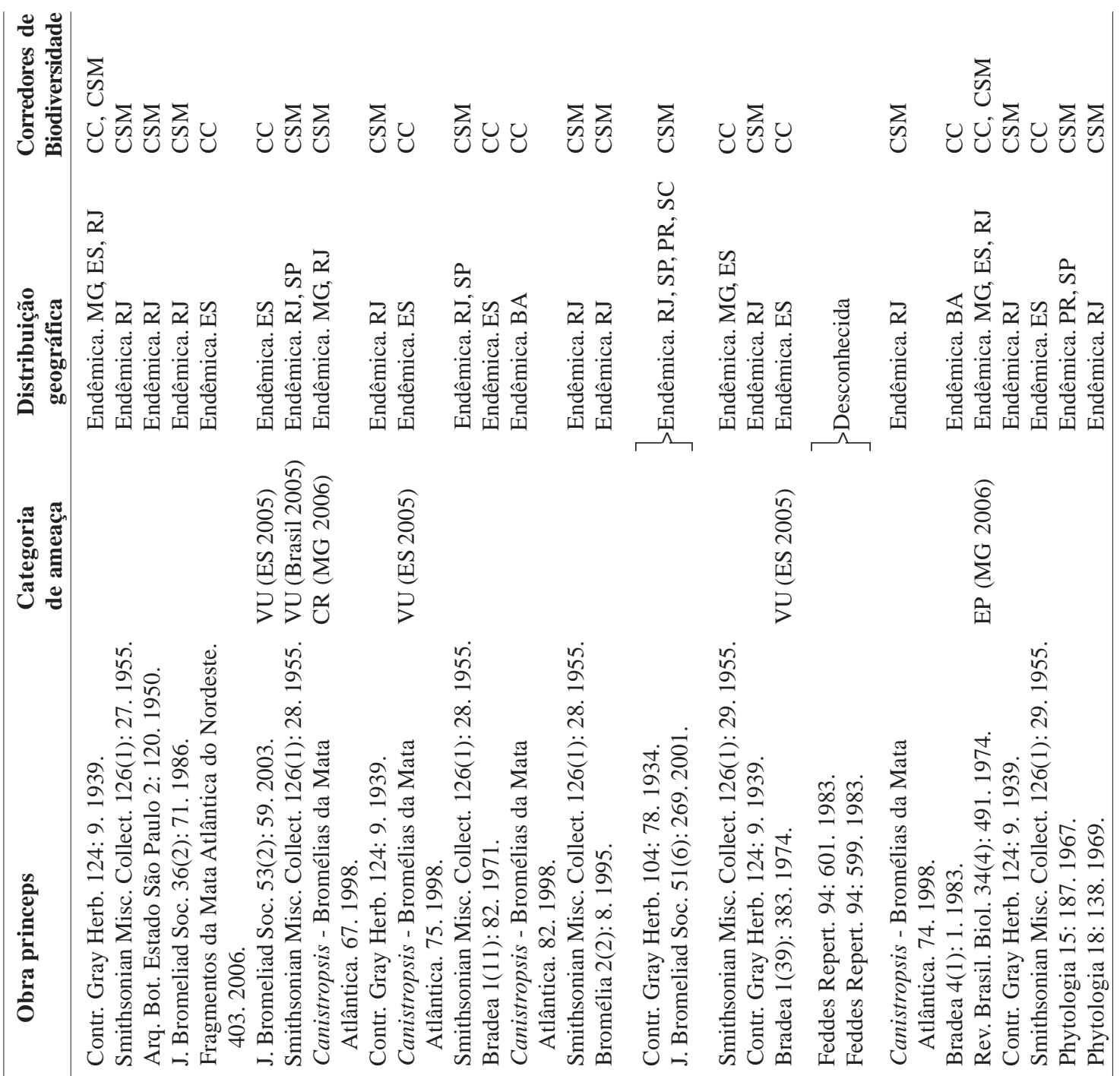




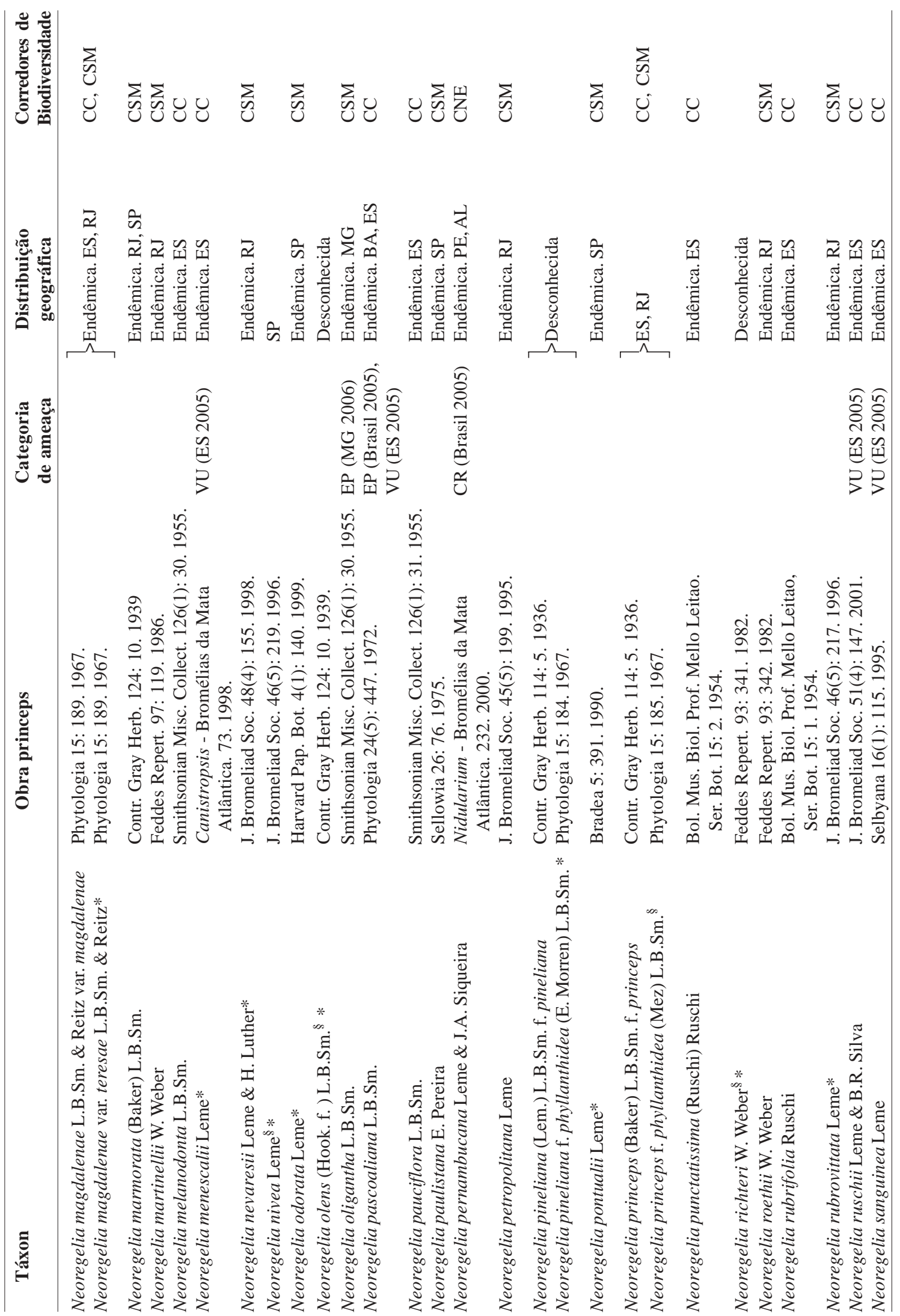

Rodriguésia 59 (1): 209-258. 2008 


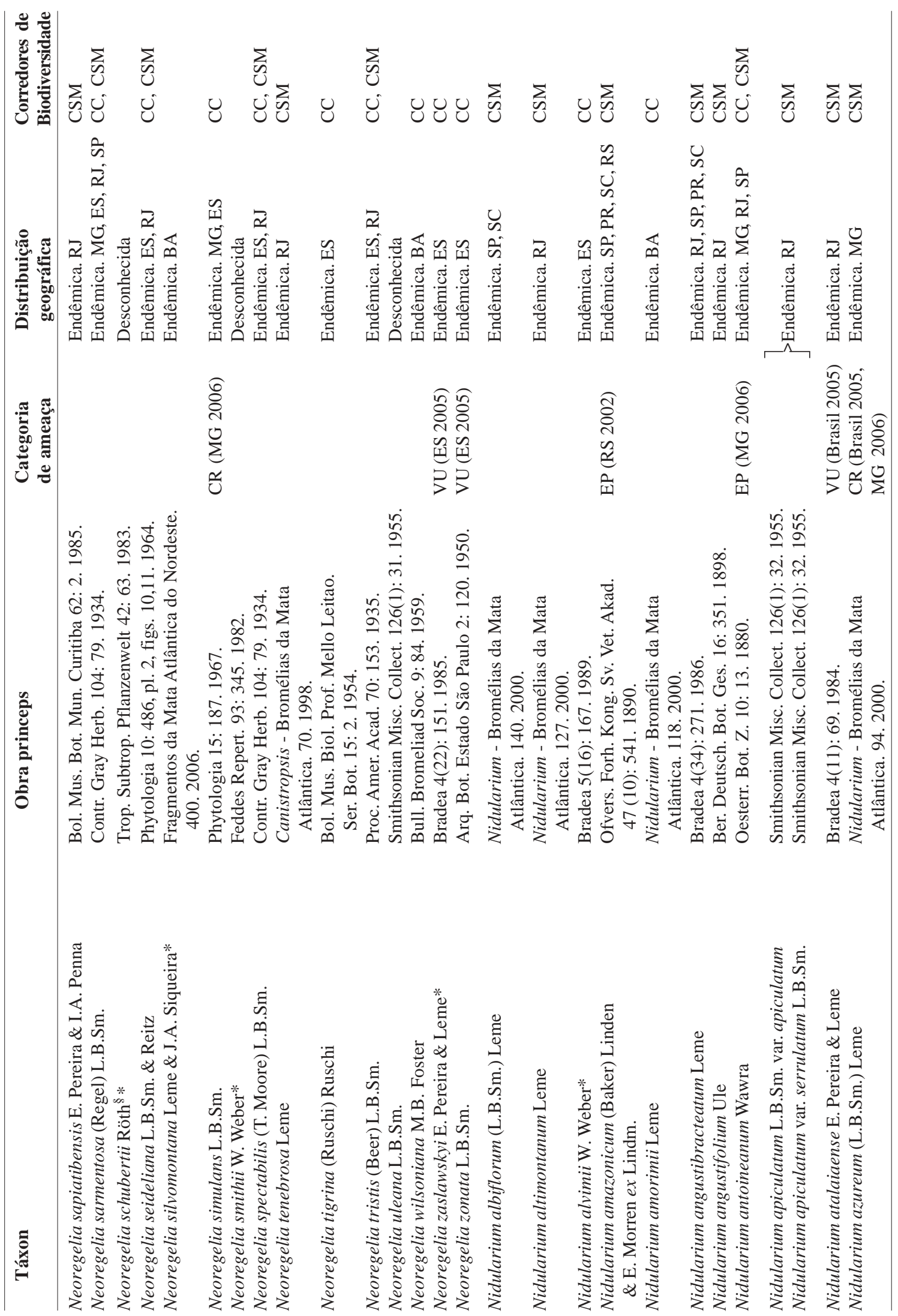




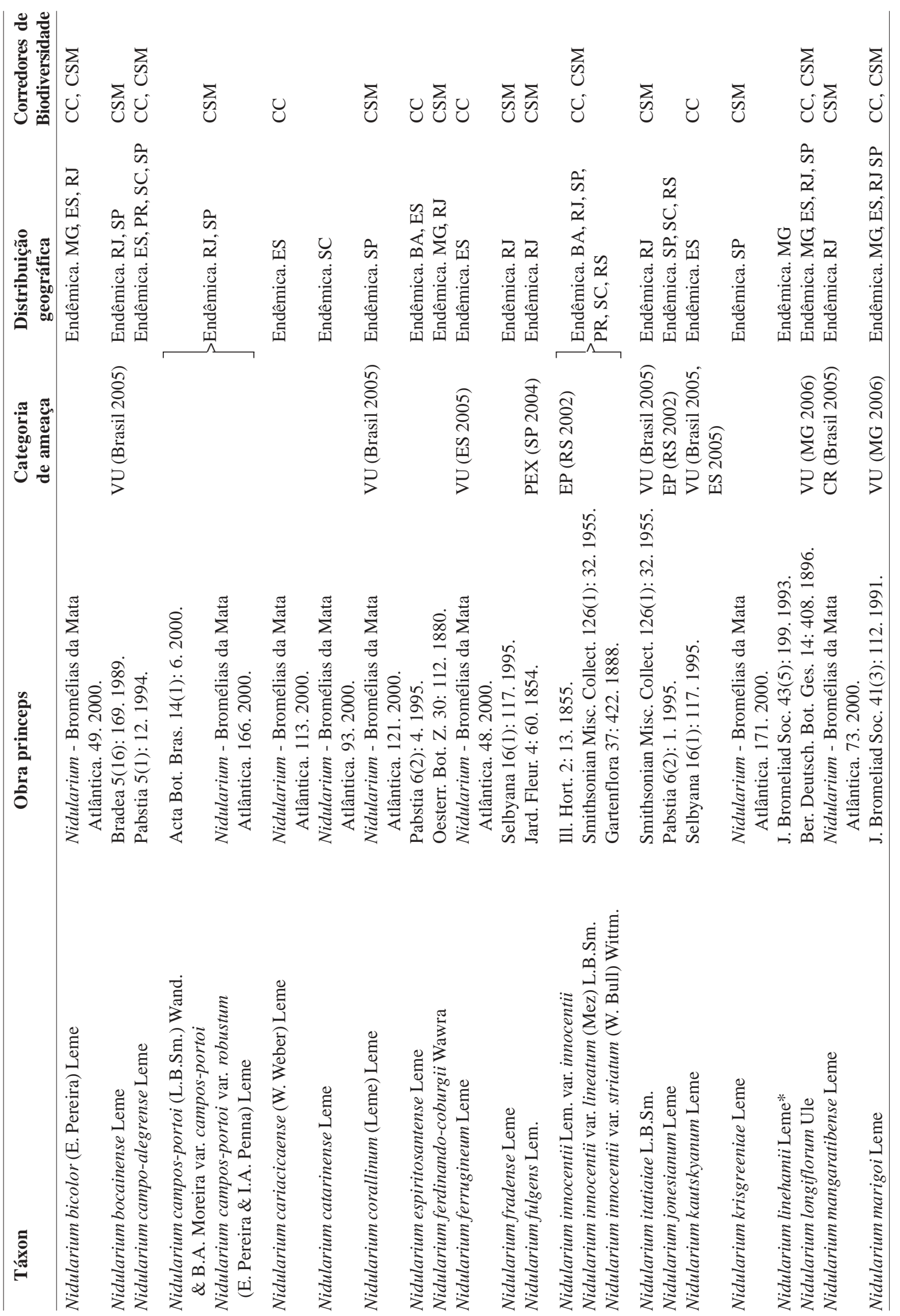

Rodriguésia 59 (1): 209-258. 2008 


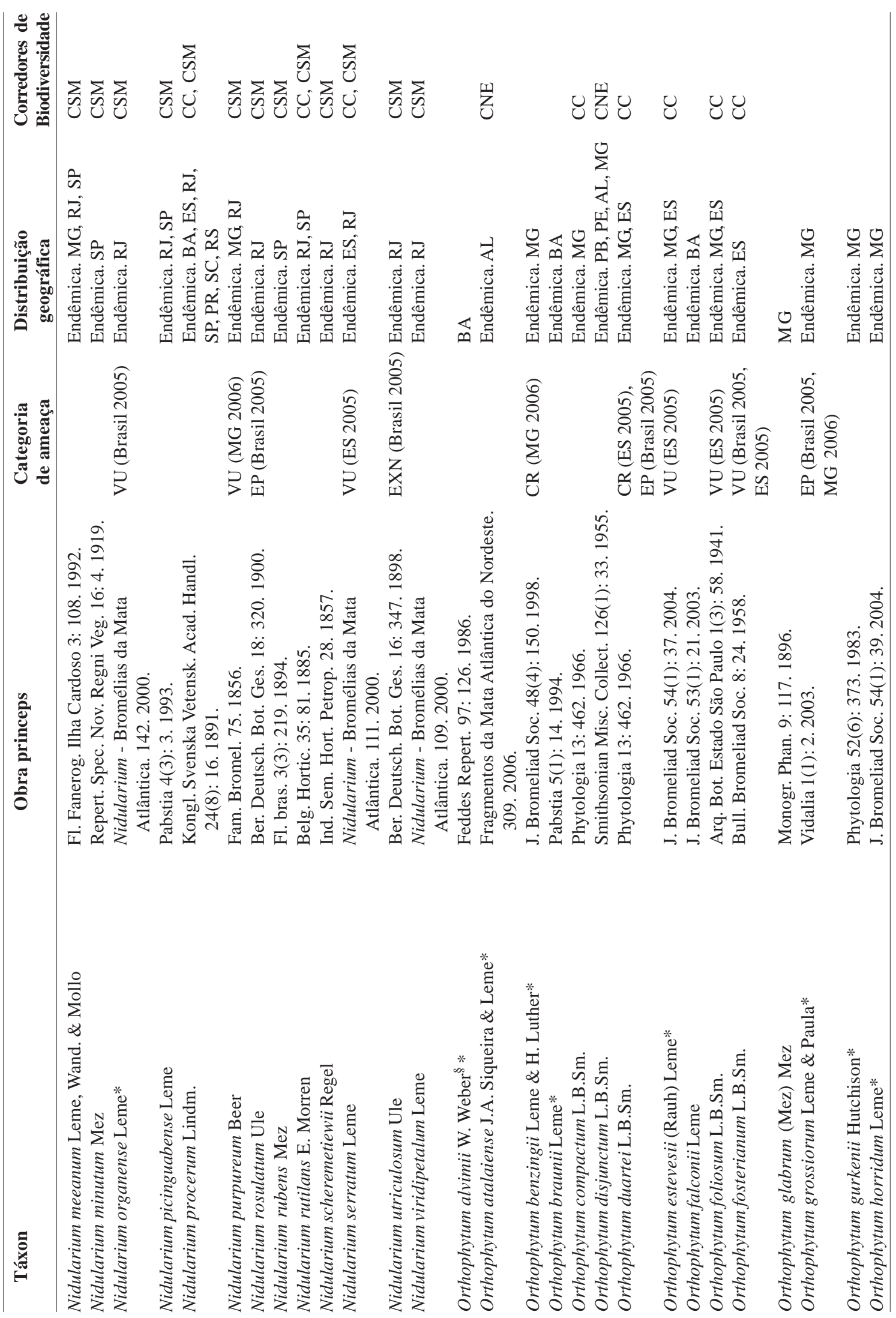




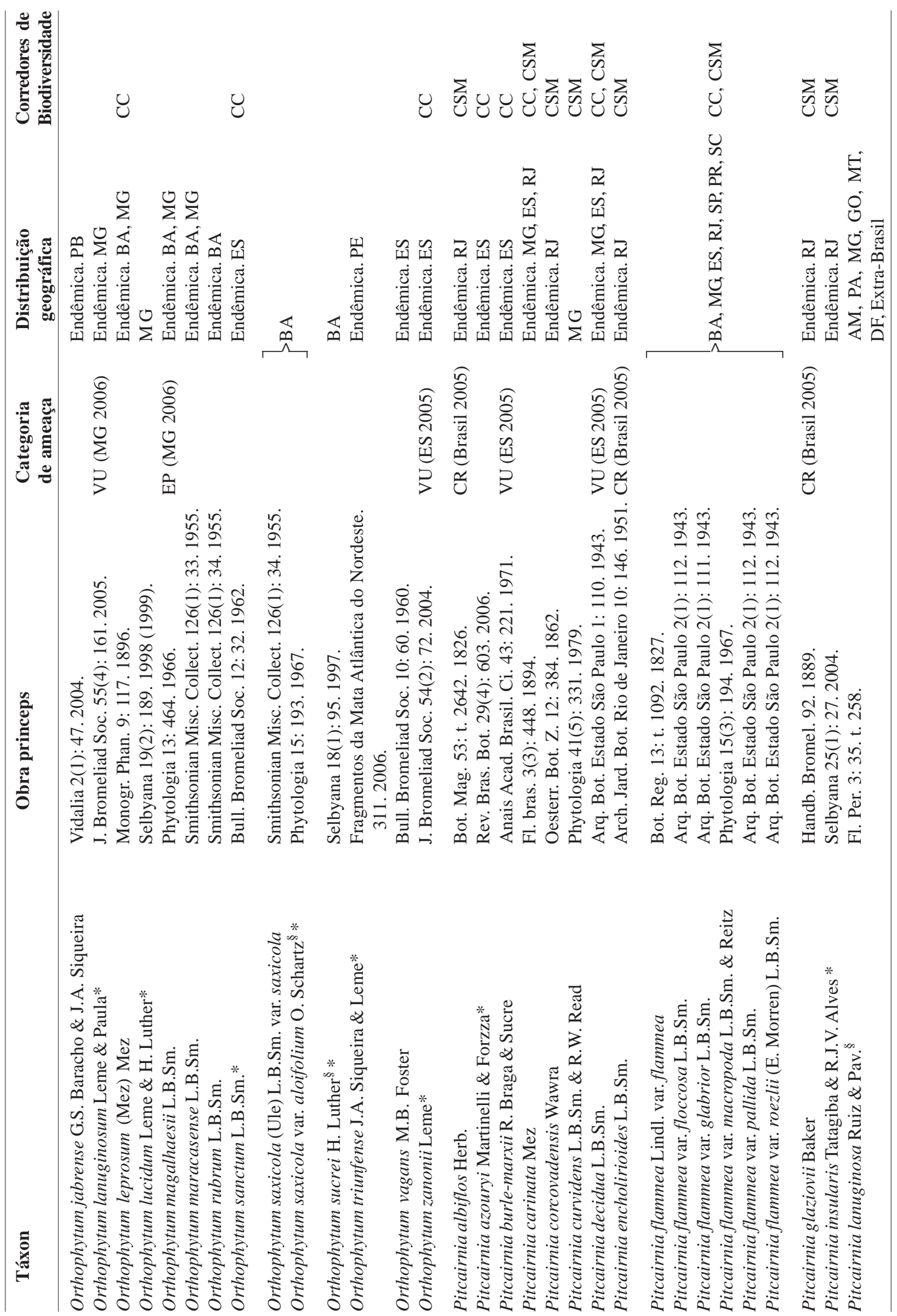




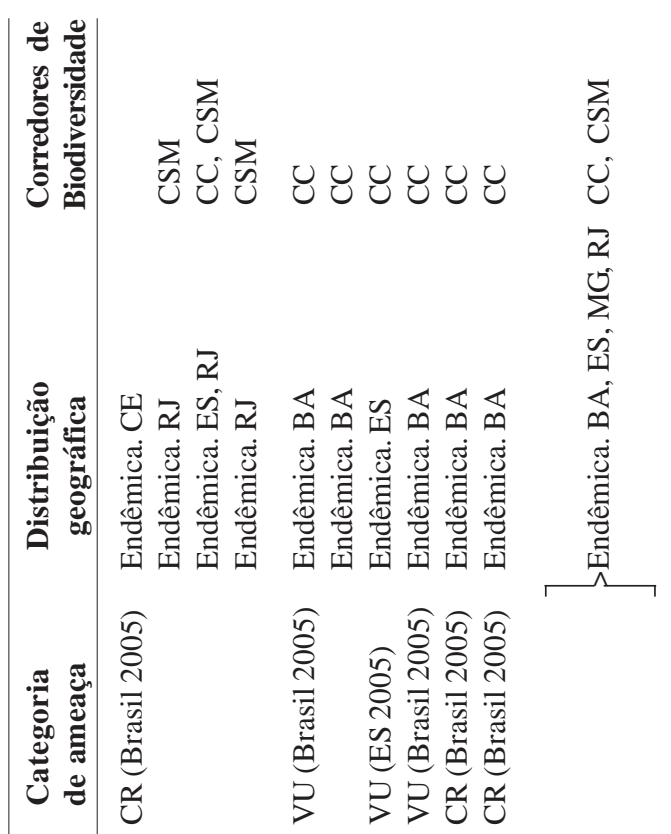

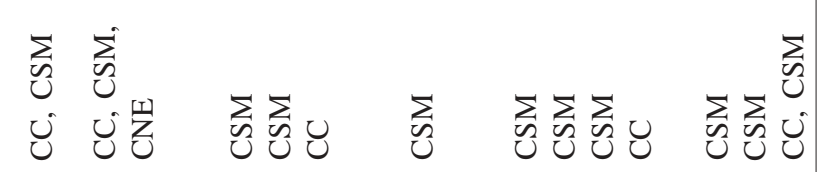

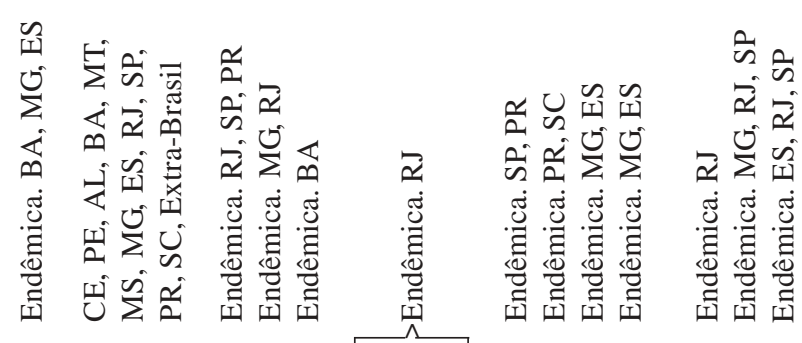
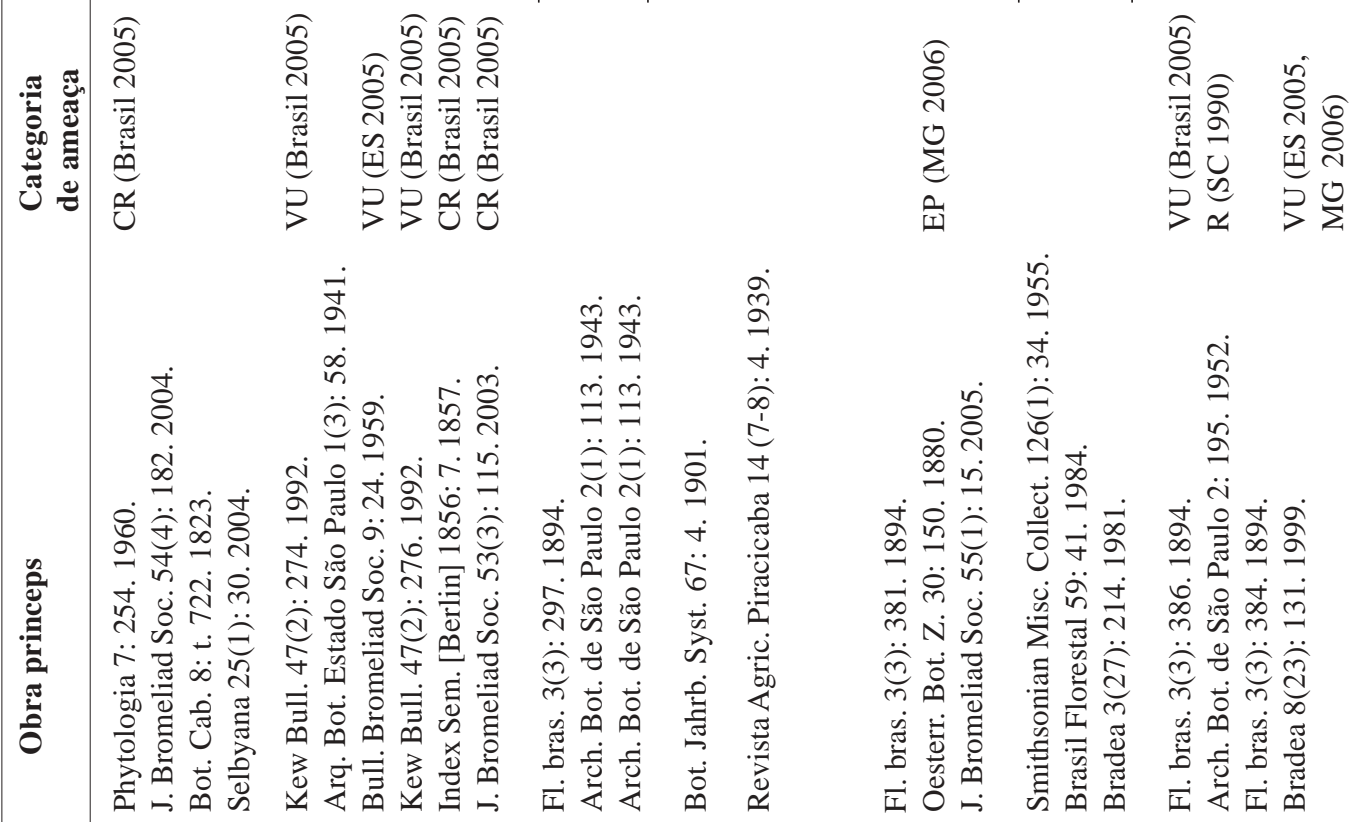

等垔
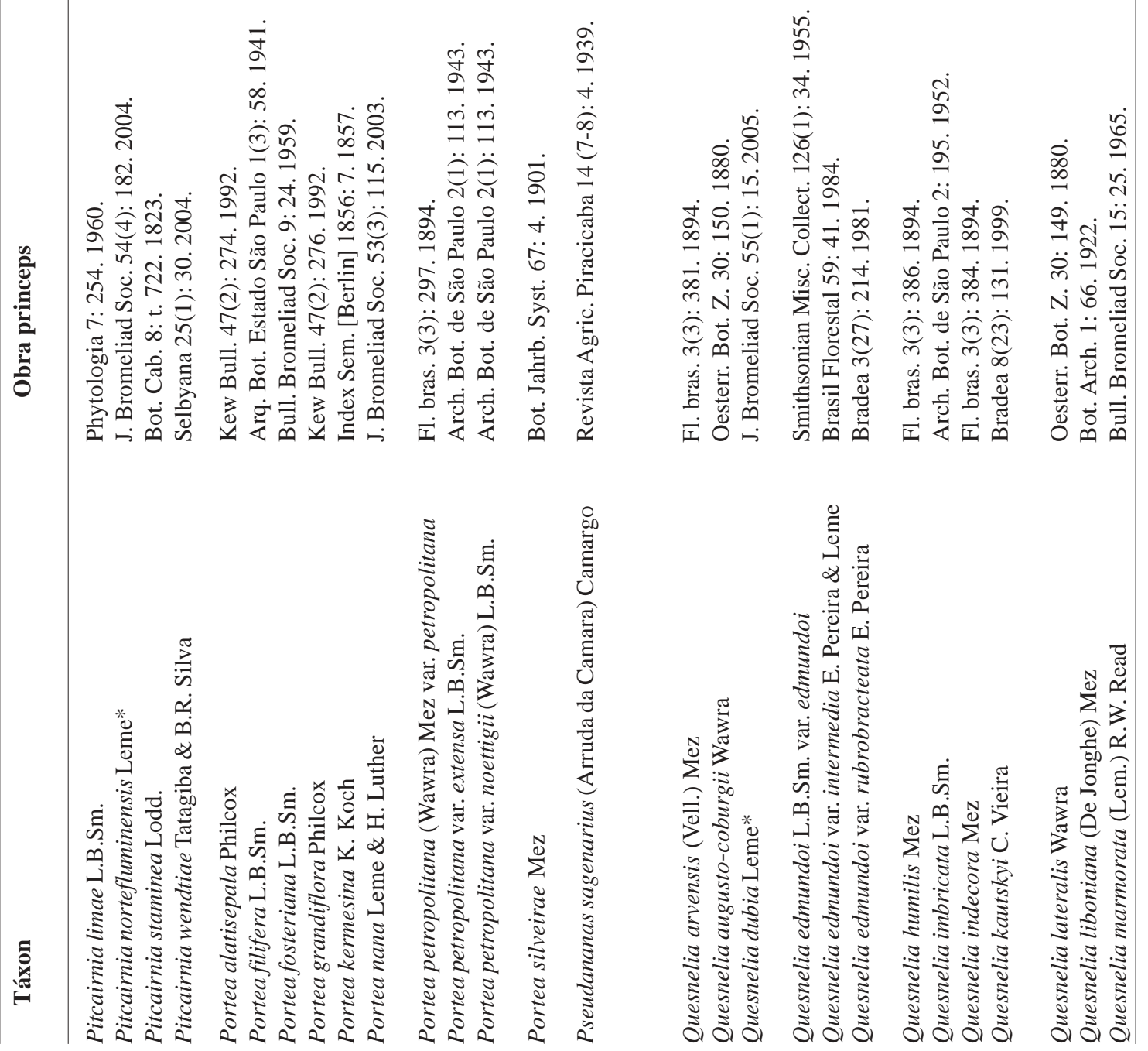

Rodriguésia 59 (1): 209-258. 2008 


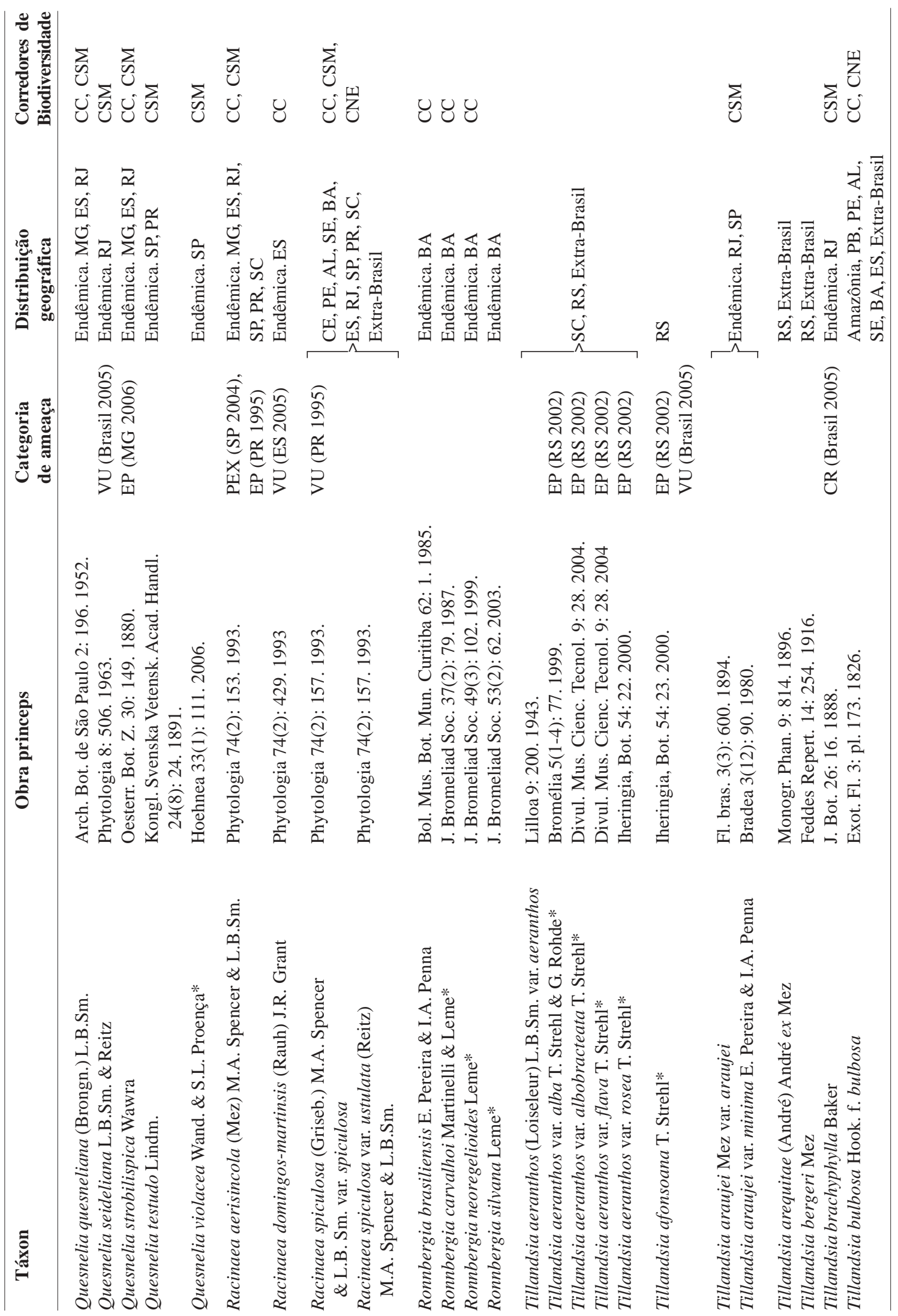




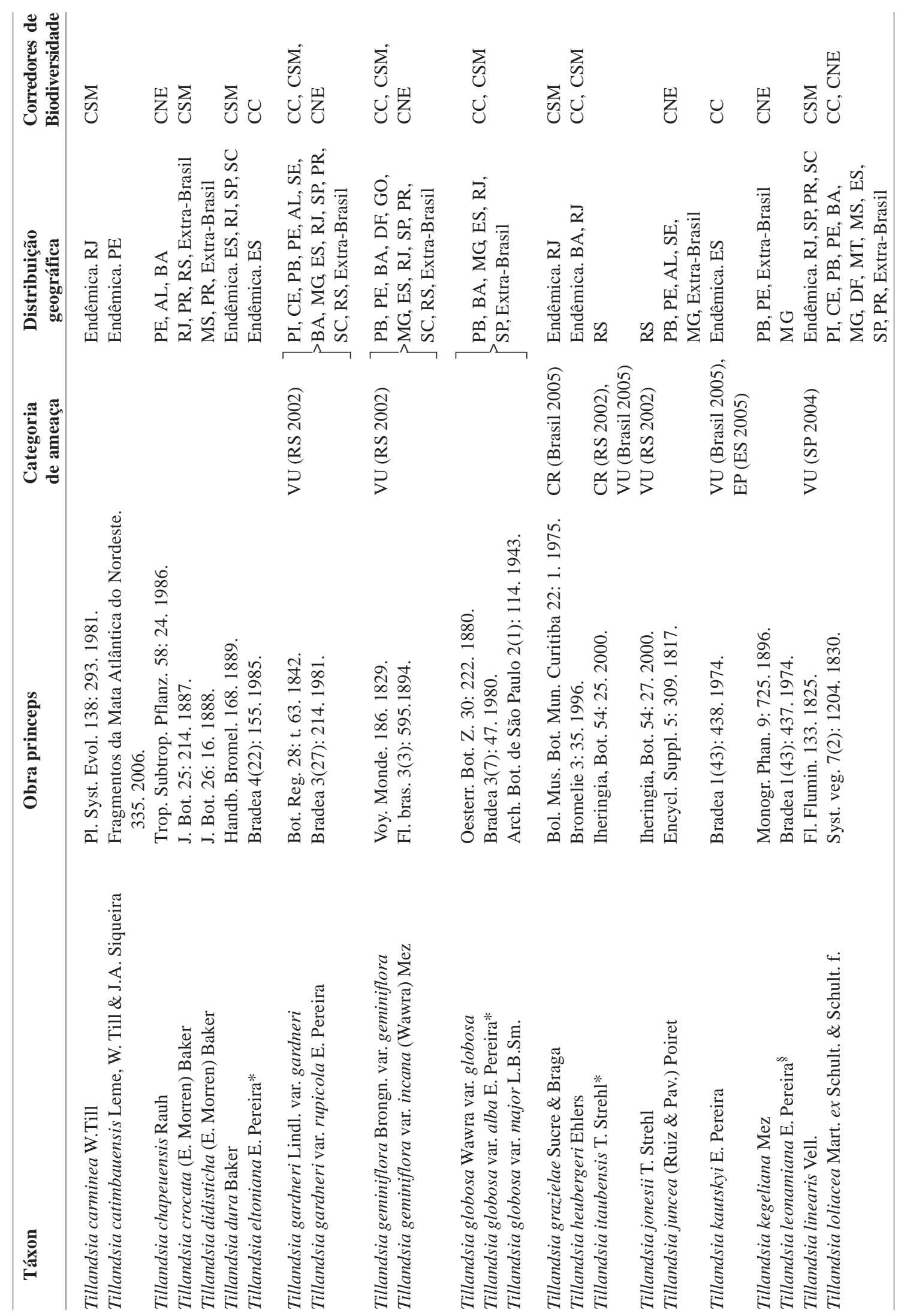




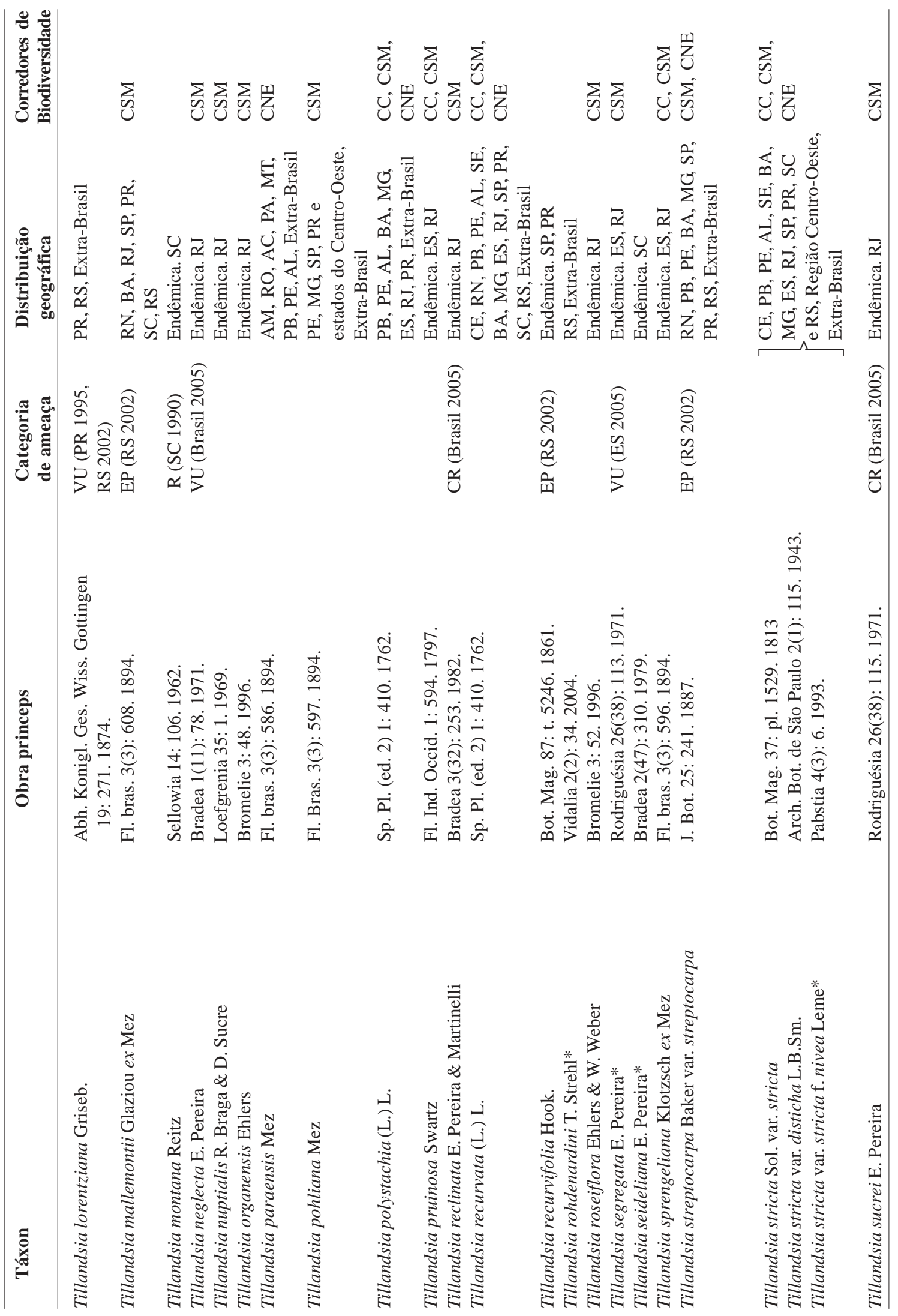

Rodriguésia 59 (1): 209-258. 2008 


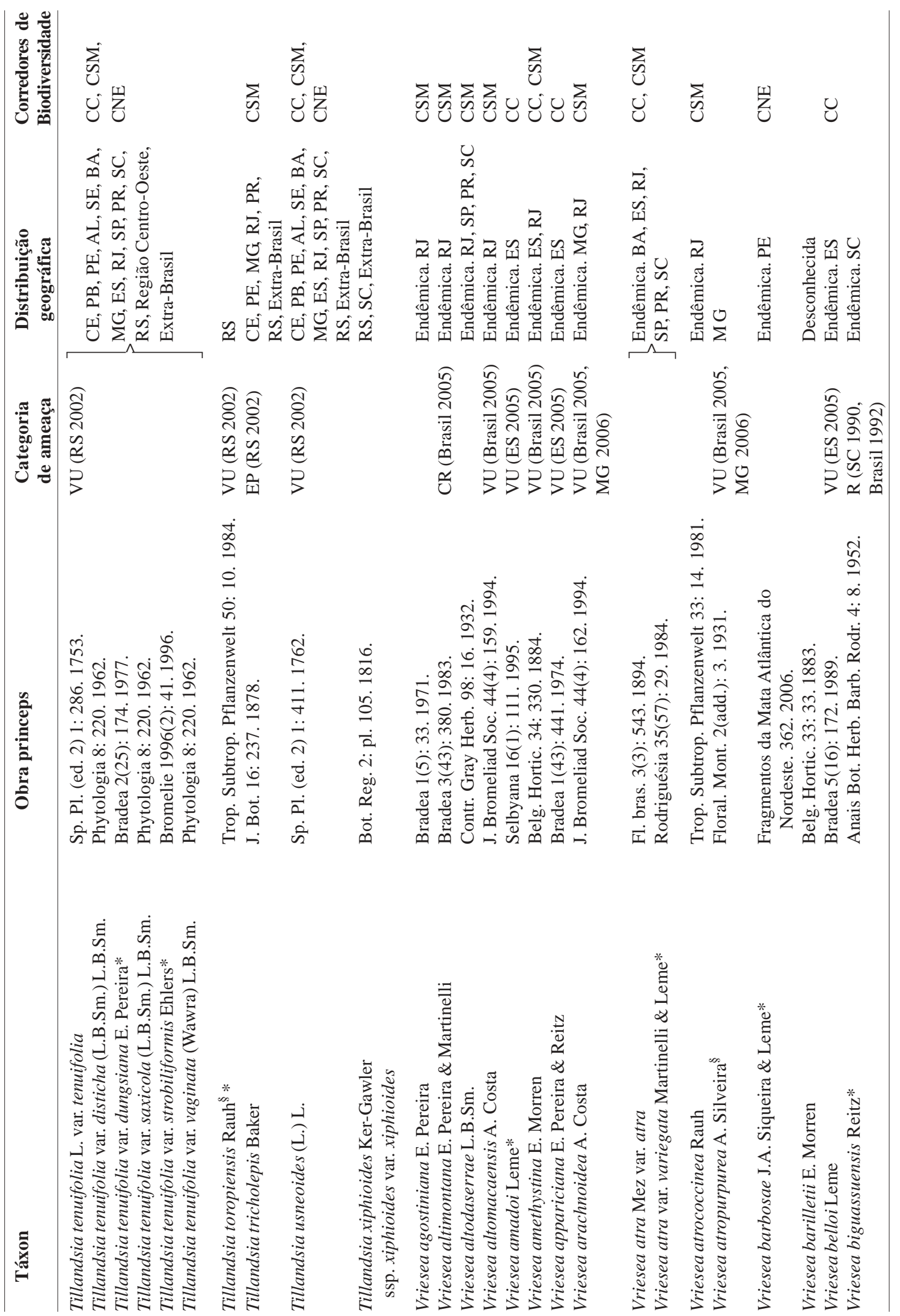




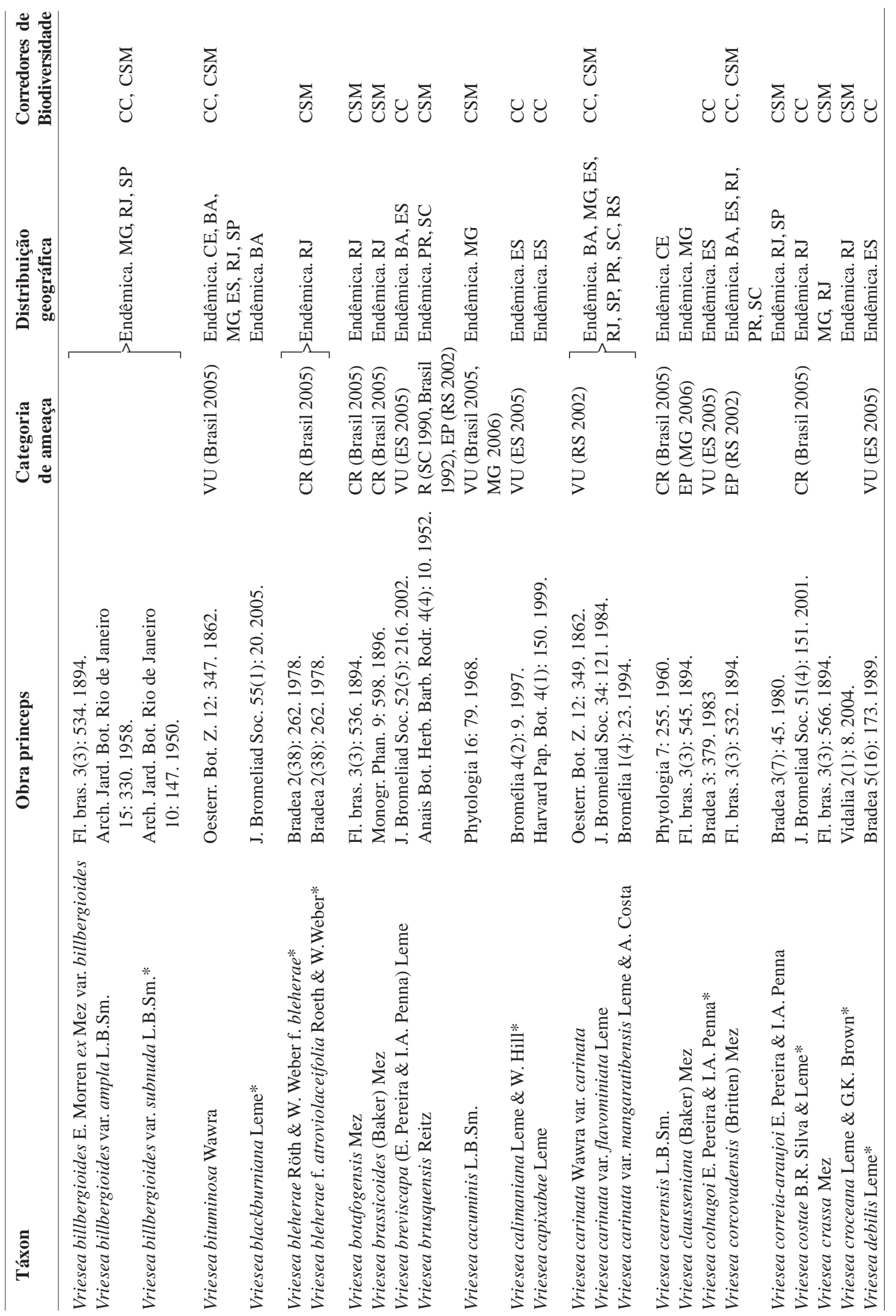




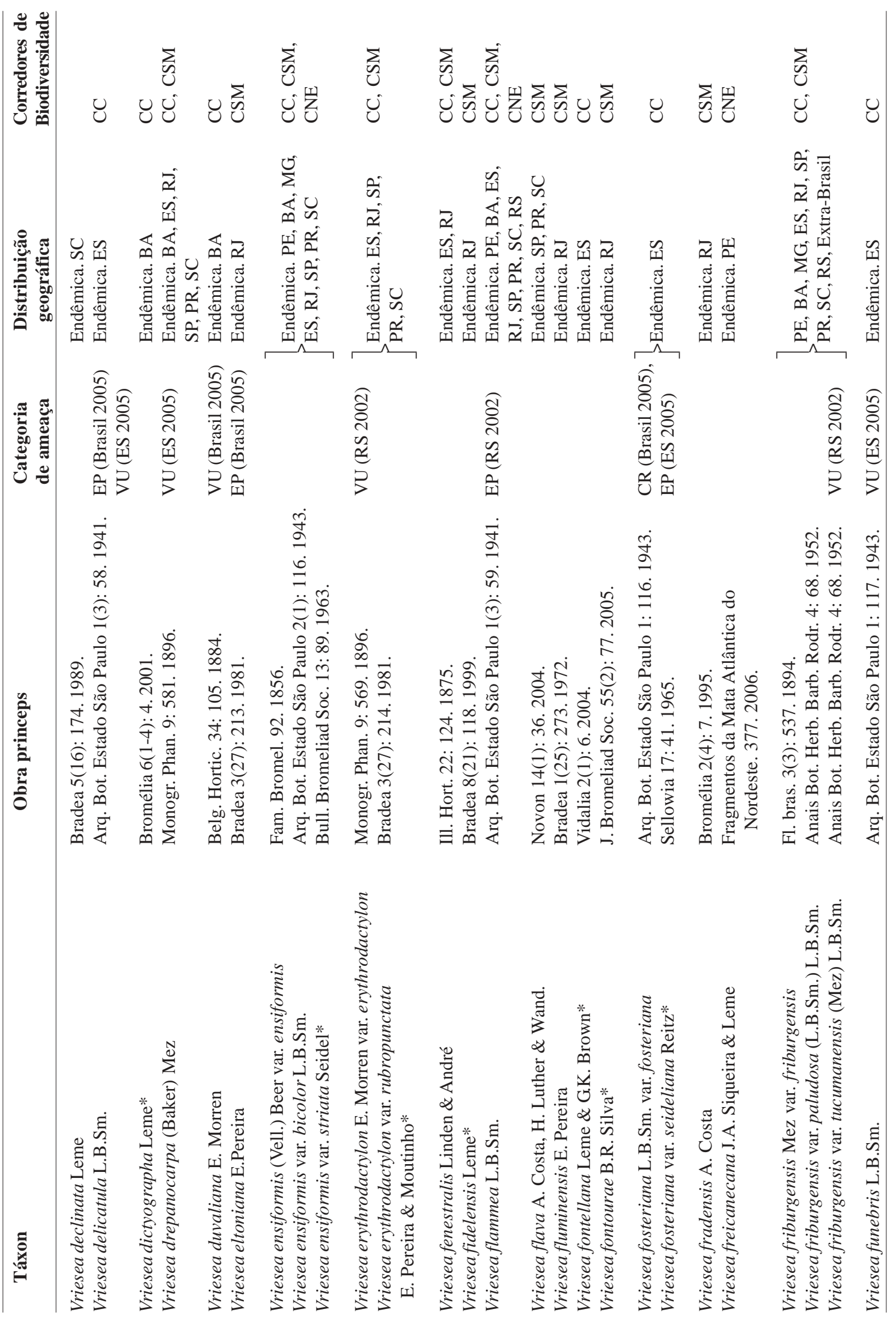




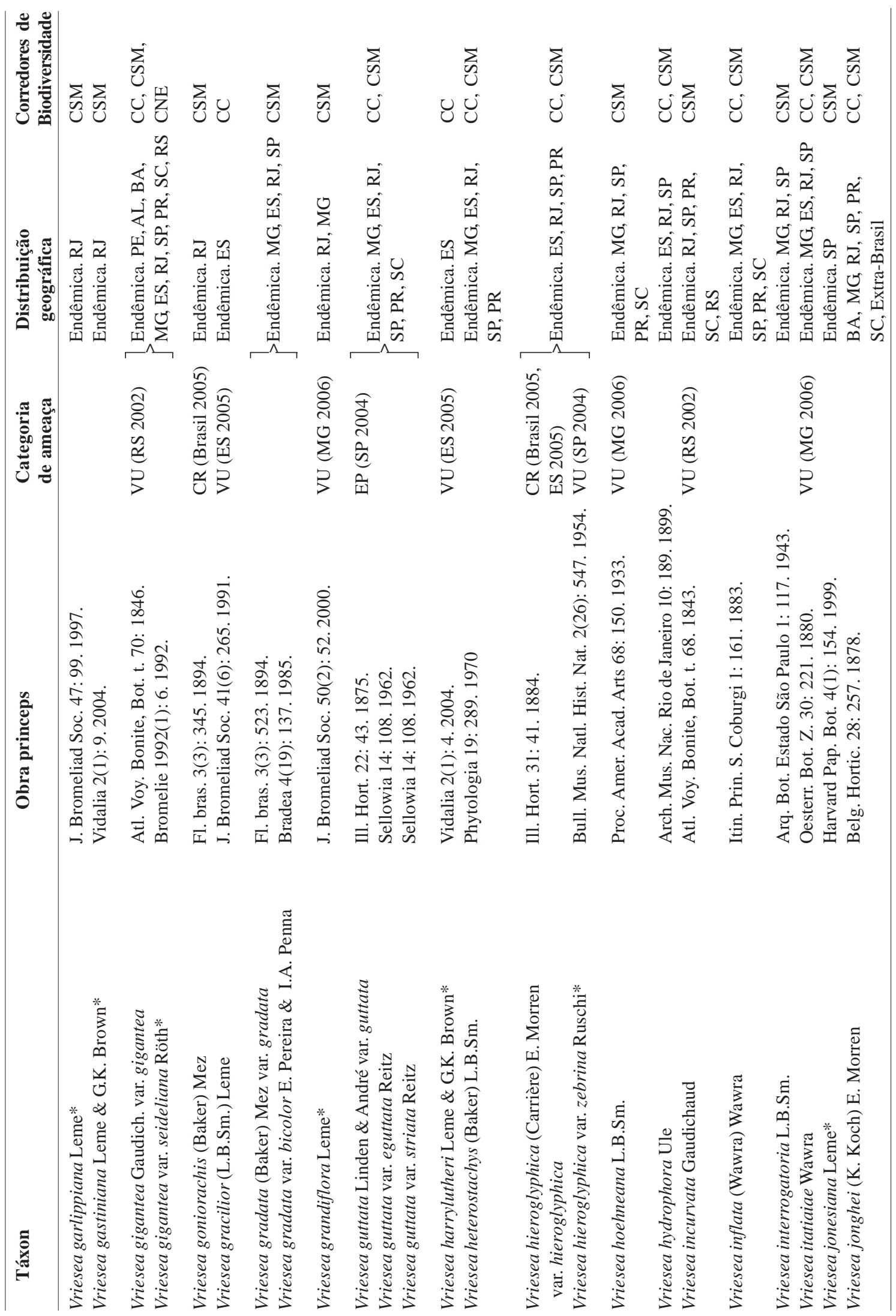

Rodriguésia 59 (1): 209-258. 2008 


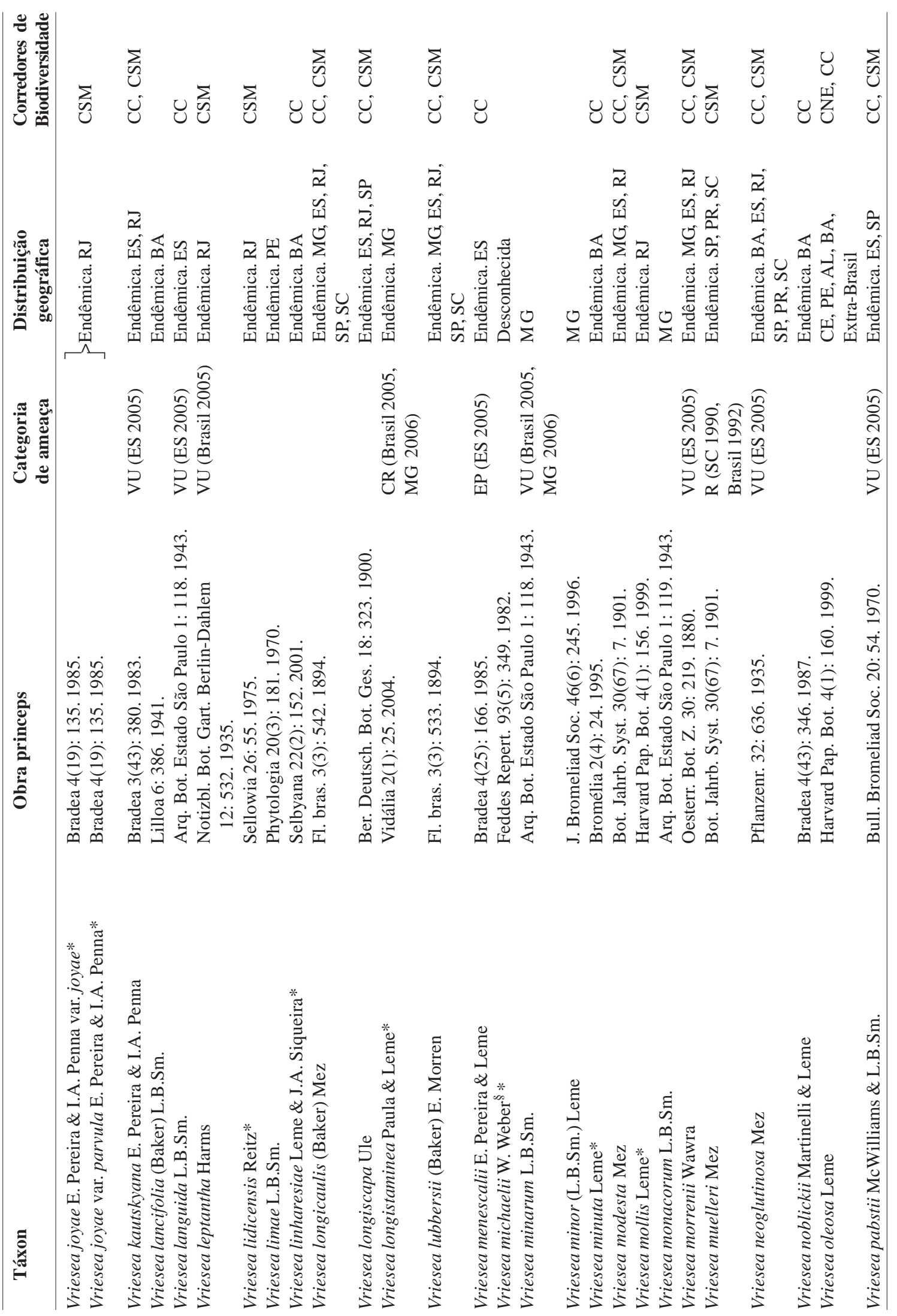




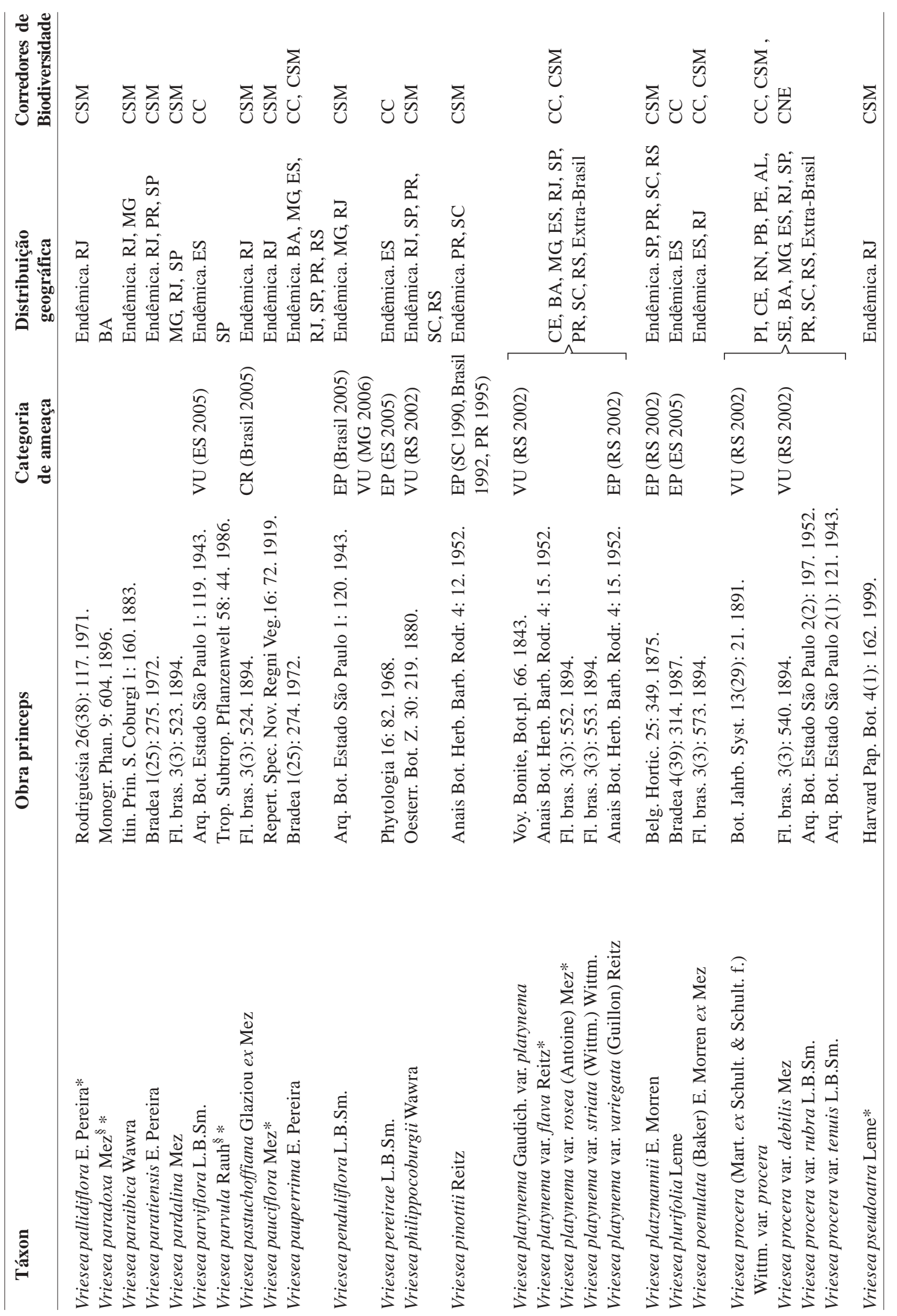

Rodriguésia 59 (1): 209-258. 2008 


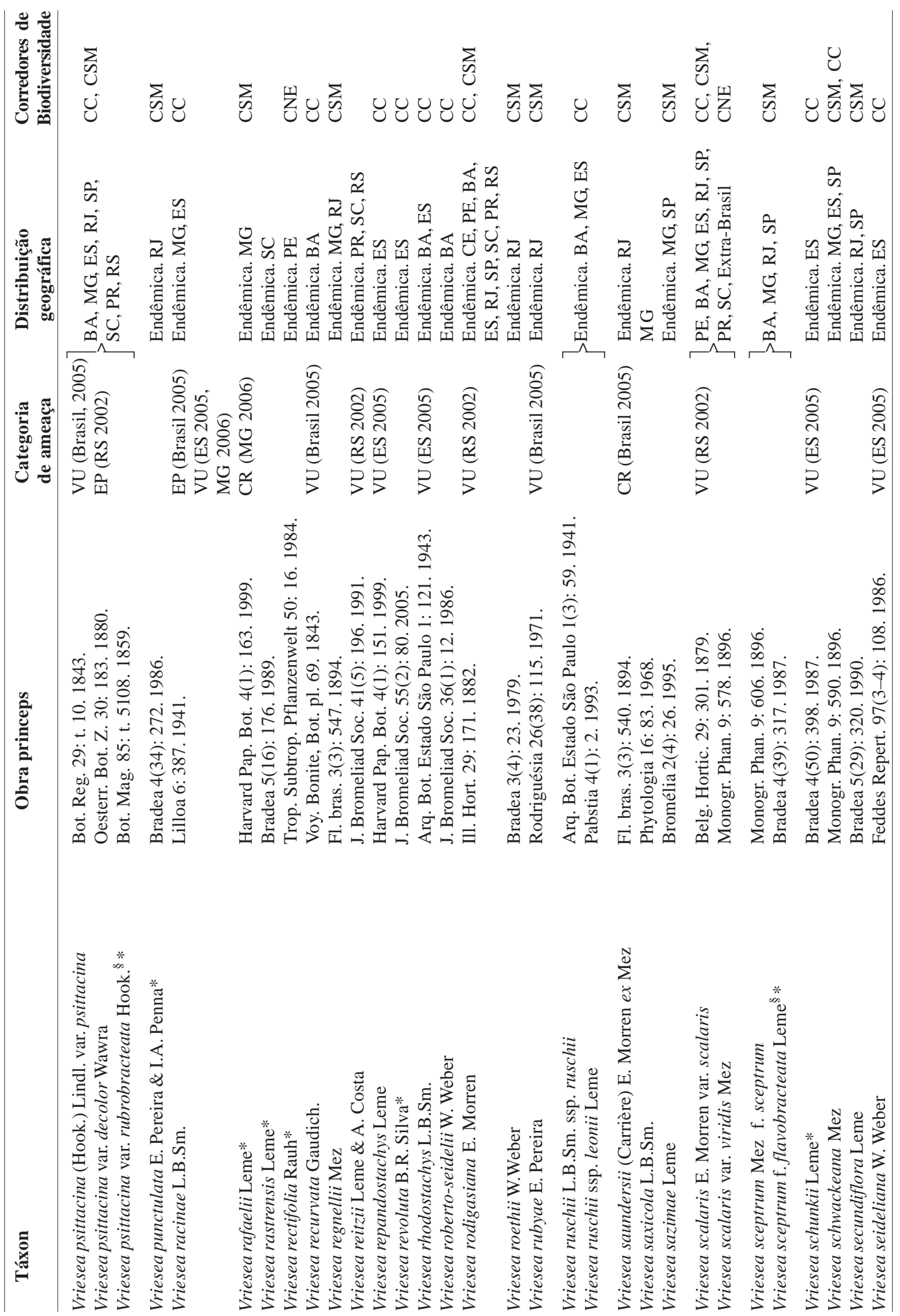




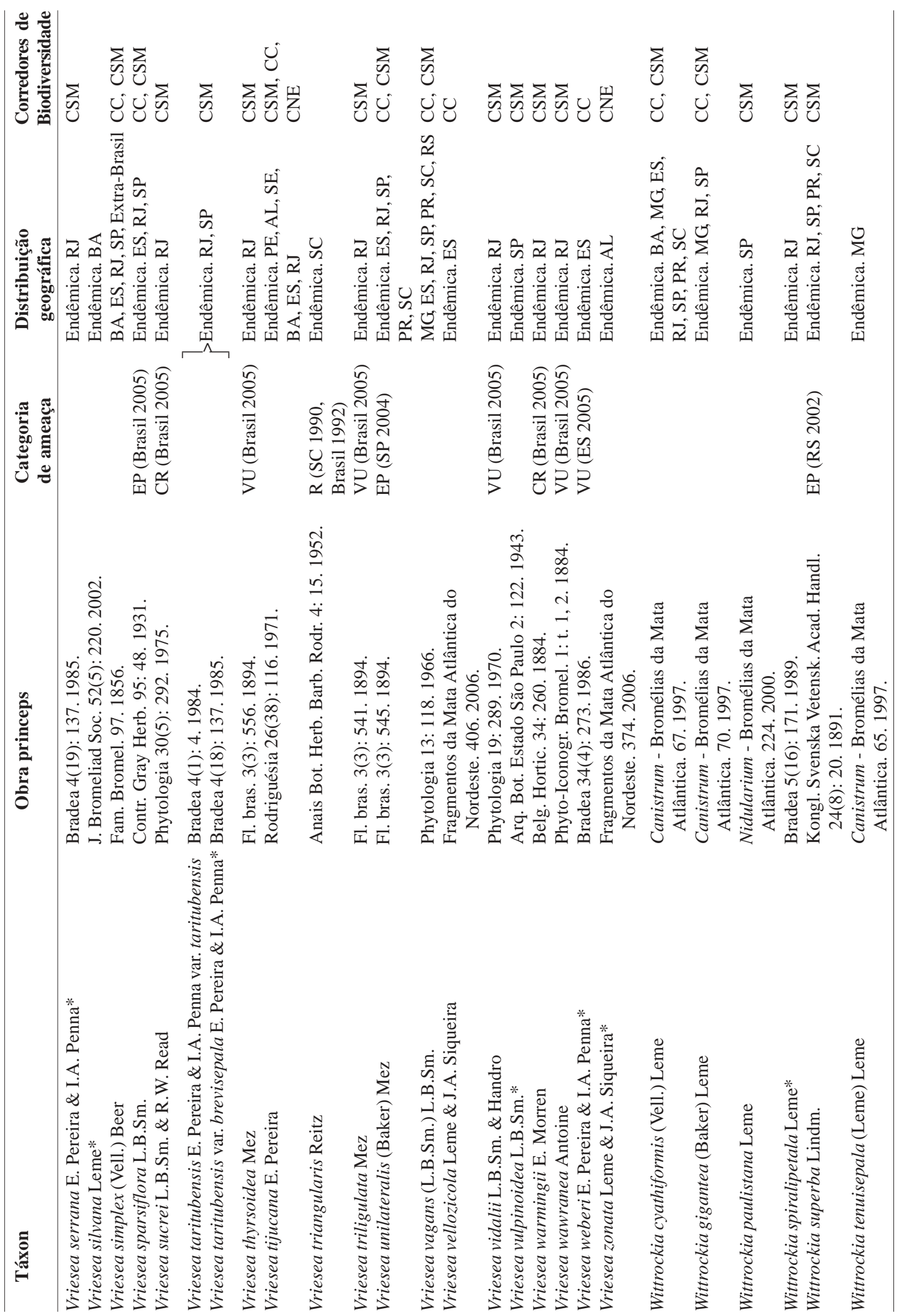


Tabela 2 - Lista de gêneros com o número total de espécies registradas no domíno da Mata Atlântica. Negrito = gênero endêmico.

\begin{tabular}{|c|c|c|c|}
\hline $\begin{array}{l}\text { Gênero/ } \mathbf{n}^{0} \text { total } \\
\text { de espécies }\end{array}$ & $\begin{array}{l}n^{\circ} \text { de espécies na } \\
\text { MataAtlântica }\end{array}$ & $\begin{array}{l}\mathbf{n}^{0} \text { de espécies endêmicas } \\
\text { da Mata Atlântica no Brasil }\end{array}$ & $\begin{array}{l}n^{0} \text { de táxons conhecidos } \\
\text { apenas pela coleção-tipo }\end{array}$ \\
\hline Vriesea (250) & 166 & 145 & 56 \\
\hline Aechmea (250) & 136 & 120 & 39 \\
\hline Neoregelia (125) & 97 & 87 & 31 \\
\hline Tillandsia (557) & 53 & 22 & 15 \\
\hline Cryptanthus (58) & 52 & 48 & 26 \\
\hline Nidularium (45) & 45 & 45 & 3 \\
\hline Billbergia (65) & 35 & 21 & 6 \\
\hline Orthophytum (40) & 28 & 23 & 15 \\
\hline Dyckia $(130)$ & 35 & 12 & 5 \\
\hline Hohenbergia (55) & 24 & 19 & 5 \\
\hline Quesnelia (16) & 16 & 16 & 2 \\
\hline Pitcairnia (350) & 16 & 13 & 3 \\
\hline Alcantarea (18) & 16 & 15 & 2 \\
\hline Canistrum (13) & 13 & 13 & 3 \\
\hline Canistropsis (11) & 11 & 11 & 1 \\
\hline Portea (8) & 8 & 8 & - \\
\hline Lymania (8) & 8 & 8 & 1 \\
\hline Bromelia (56) & 6 & 1 & - \\
\hline Wittrockia (6) & 6 & 6 & 1 \\
\hline Ananas (7) & 3 & 1 & - \\
\hline Ronnbergia (14) & 4 & 4 & 3 \\
\hline Edmundoa (3) & 3 & 3 & - \\
\hline Guzmania (200) & 3 & - & - \\
\hline Racinaea (58) & 3 & 2 & - \\
\hline Acanthostachys (2) & 2 & - & - \\
\hline Araeococcus (9) & 5 & 5 & 1 \\
\hline Encholirium (23) & 3 & 2 & - \\
\hline Catopsis (18) & 2 & - & - \\
\hline Fernseea (2) & 2 & 2 & - \\
\hline Andrea (1) & 1 & 1 & - \\
\hline Pseudananas (1) & 1 & - & - \\
\hline Total & 803 & 653 & 218 \\
\hline
\end{tabular}

Tabela 3 - Riqueza, endemismo e número de espécies ameaçadas nos corredores da biodiversidade da Mata Atlântica. $\mathrm{CNE}=$ Corredor do Nordeste $; \mathrm{CC}=$ Corredor Central CSM = Corredor da Serra do Mar. * Percentual em relação ao total de espécies da Mata Atlântica (803); ** Percentual em relação ao total de espécies em cada corredor ou nos três corredores; *** Percentual em relação ao total de espécies ameaçadas para a Mata Atlântica (319).

\begin{tabular}{lllcc}
\hline Corredores & $\begin{array}{c}\text { Total } \\
\text { spp. }(\% *)\end{array}$ & $\begin{array}{c}\text { Endêmicas } \\
\text { MA }(\% * *)\end{array}$ & $\begin{array}{c}\text { Total spp. } \\
\text { ameaçadas (\%***) }\end{array}$ & $\begin{array}{c}\text { Ameaçadas e } \\
\text { endêmicas MA (\%***) }\end{array}$ \\
\hline Corredores CC, CSM ou CNE & $671(83,6 \%)$ & $585(87,2 \%)$ & $265(84,1 \%)$ & $238(75,6 \%)$ \\
Corredor Central & $396(49,3 \%)$ & $336(84,8 \%)$ & $166(52,7 \%)$ & $149(47,3 \%)$ \\
Corredor da Serra do Mar & $369(46 \%)$ & $309(83,7 \%)$ & $143(45,4 \%)$ & $117(37,1 \%)$ \\
Corredor do Nordeste & $86(10,7 \%)$ & $53(61,6 \%)$ & $24(7,6 \%)$ & $14(4,4 \%)$ \\
\hline
\end{tabular}




\section{Agradecimentos}

Ao Instituto de Pesquisas Jardim Botânico do Rio de Janeiro, ao Critical Ecosystem Partnership Fund (CEPF), à Fundação Botânica Margaret Mee (FBMM) e à Aliança para a Conservação da Mata Atlântica pelo patrocínio e apoio. Aos curadores dos herbários, pela sempre atenciosa recepção. Aos especialistas na família que contribuíram com valiosas sugestões durante o "Workshop Estratégias e Abordagens para a Conservação de Bromeliaceae da Mata Atlântica". A Denise Pinheiro da Costa e aos dois assessores anônimos pelas diversas sugestões.

\section{REFERÊNCIAS BIBLIOGRÁFICAS}

Aguiar, A. P.; Chiarello, A. G.; Mendes, S. L. \& Matos, E. N. 2003. The Central and Serra do Mar Corridors in the Brazilian Atlantic Forest. In: Galindo-Leal, C. \& Camara, I. G. (orgs.). The Atlantic Forest of South America: Biodiversity Status, Threats and Outlook Center for Applied Biodiversity Science at Conservation International. Island Press, Washington. Pp. 118-132.

Amorim, A. M. A.; Fiaschi, P.; Jardim, J. G.; Thomas, W. W.; Clifton, B. C. \& Carvalho, A. M. V. 2005. The vascular plants of a forest fragment in Southern Bahia, Brazil. Sida 21(3): 1727-1757.

Araújo, D.S.D. 2000. Análise florística e fitogeográfica das restingas do Estado do Rio de Janeiro. Tese de Doutorado. Universidade Federal do Rio de Janeiro. Rio de Janeiro, 176p.

Assis, A. M.; Thomas, L.D. \& Pereira, O. J. 2004. Florística de um trecho de floresta de restinga no Município de Guarapari, Espírito Santo, Brasil. Acta Botanica Brasilica 18(1): 191-201.

Ayres, J. M.; Fonseca, G. A. B.; Rylands, A. B.; Queiroz, H. L.; Pinto, L. P.; Masterson, D. \& Cavalcanti, R. B. 2005. Os corredores ecológicos das florestas tropicais do Brasil. Sociedade Civil Maminaurá, Belém, 256p.

Barros J. V. 2006. O gênero Billbergia Thunb. (Bromeliaceae, Bromelioideae) no estado do Rio de Janeiro. Dissertação de Mestrado. Universidade Federal do Rio de Janeiro. Rio de Janeiro. 132 p.

Barrros, F.; Melo, M. M. R. F.; Chiea, S. A. C.; Kirizawa, M.; Wandereley, M. G. L. \& Jung-Mendaçolli, S. L. 1991. Caracterização geral da vegetação e listagem das espécies ocorrentes. In: Melo, M. M. R. F.; Barros, F.; Wanderley, M. G. L.; Kirizawa, M.; Jung-Mendaçolli, S. L. \& Chiea, S. A. C. (eds.). Flora Fanerogâmica da Ilha do Cardoso. Vol. 1. Instituto de Botânica, São Paulo, 184p.

Bonnet, A. \& Queiroz, M. H. 2006. Estratificação vertical de bromélias epifíticas em diferentes estádios sucessionais da Floresta Ombrófila Densa, Ilha de Santa Catarina, Santa Catarina, Brasil. Revista Brasileira de Botânica 29(2): 217-228.

Borgo, M. \& Silva, S. M. 2003. Epífitos vasculares em fragmentos de Floresta Ombrófila Mista, Curitiba, Paraná, Brasil. Revista Brasileira de Botânica 26(3): 391-401.

Cabrera, A. L. \& Willink, A. 1973. Biogeografia de América Latina. Secretaria General de la Organización de los Estados Americanos, Washington, 231p.

Clarke, H. D. \& Funk, V. A. 2005. Using checklists and collections data to investigate plant diversity: An analysis of five florulas from northeastern South America. Proceedings of the Academy of Natural Sciences of Philadelphia 154: 29-37.

CN-RBMA, 2004. www.rbma.org.br

Cogliatti-Carvalho, L.; Freitas, A. F. N.; Rocha, C. F. D. \& van Sluys, M. 2001. Variação na estrutura e na composição de Bromeliaceae em cinco zonas de restinga no Parque Nacional da Restinga de 
Jurubatiba, Macaé, RJ. Revista Brasileira de Botânica 24(1): 1-9.

Costa, A. F. 2002. Revisão taxonômica do complexo Vriesea paraibica Wawra (Bromeliaceae). Tese de Doutorado. Universidade de São Paulo, São Paulo, 187p.

Costa; A. F. \& Dias, I. C. A. (orgs.). Flora do Parque Nacional da restinga de Jurubatiba e arredores, RJ: listagem, florística e fitogeografia (Angiospermas, Pteridófitas e Algas continentais). Museu Nacional/ UFRJ, Rio de Janeiro, 200p.

Costa, A. F. \& Wendt, T. 2007. Bromeliaceae na região de Macaé de Cima, Nova Friburgo, Rio de Janeiro. Rodriguésia 58(4): 905-939.

Faria, A. P. G. 2006. Revisão taxonômica de filogenia de Aechmea Ruiz \& Pav. subg. Macrochordion (De Vriese) Baker, Bromelioideae - Bromeliaceae. Tese de Doutorado. Universidade Federal do Rio de Janeiro, Rio de Janeiro, 199p.

Faria, A. P. G.; Wendt, T. \& Brown, G. K. 2004. Cladistic relationships of Aechmea (Bromeliaceae, Bromelioideae) and allied genera. Annals of the Missouri Botanical Garden 91: 303-319.

Fraga, C. N.; Simonelli, M. \& Fernandes, H. Q. B. 2007. Metodologia utilizada na elaboração da lista da flora ameaçada de extinção no Espírito Santo. In: Fraga, C. N. \& Simonelli, M. (orgs.). Espécies da flora ameaçadas de extinção no estado Espírito Santo. IPEMA, Vitória. Pp. 59-72.

Fontoura, T. 2005. Distribuição geográfica, forófitos e espécies de bromélias epífitas nas matas e plantações de cacau na região de Una, Bahia. Tese de Doutorado. Universidade Estadual de Campinas, Campinas, 84p.

Fontoura, T.; Costa, A. \& Wendt, T. 1991. Preliminary checklist of the Bromeliaceae of Rio de Janeiro State, Brazil. Selbyana 12: 5-45.

Forzza, R. C. 2005. Revisão taxonômica de Encholirium Mart. ex Schult. \& Schult. f.
(Pitcairnioideae-Bromeliaceae). Boletim de Botânica da Universidade de São Paulo 23(1): 1-49.

Fonseca G. A. B.; Alger, K.; Pinto, L. P. \& Cavalcanti, R. 2004. Corredores de Biodiversidade: o corredor Central da Mata Atlântica. In: Arruda, M. B. \& Sá, L. F. S. N. (orgs.). Corredores ecológicos: uma visão integradora de ecossistemas. Ibama, Ministério do Meio Ambiente. Pp. 47-65.

Giongo, C. \& Waechter, J. L. 2004. Composição florística e estrutura comunitária de epífitos vasculares em uma floresta de galeria na Depressão Central do Rio Grande do Sul. Revista Brasileira de Botânica 27(3): 563-572.

Givnish, T. J.; Millam, K. C.; Berry, P. E. \& Sytsma, K. J. 2005. Phylogeny, adaptive radiation, and historical biogeography of Bromeliaceae inferred from $n d h F$ sequence data. In: Columbus, J. T.; Friar, E. A.; Hamilton, C. W.; Porter, J. M.; Prince, L. M. \& Simpson, M. G. (eds.). Monocots: Comparative Biology and Evolution (3 vols.). Rancho Santa Ana Botanic Garden, Claremont. Pp. 3-26.

GSPC. 2005. Estratégia global para a conservação de plantas. RBJB/JBRJ/BGCI, 13p.

Holmgren, P. K. \& Holmgren, N. H. 1998 [continuously updated]. Index Herbariorum: A global directory of public herbaria and associated staff. New York Botanical Garden's Virtual Herbarium. http:// sweetgum.nybg.org/ih/

IBAMA. 1992. Portaria $n^{\circ} 06-\mathrm{N}$ de 15 de Janeiro de 1992. Lista oficial de espécies da flora brasileira ameaçadas de extinção.

IEMA. 2005. Lista oficial das espécies da flora do estado do Espírito Santo ameaçadas de extinção. Decreto Estadual no 1499-R publicado no Diário Oficial do Estado no dia 14 de junho de 2005.

IOPI. 2006. International Organization for Plant Information: The Global Plant Checklist Project. 2006: http://www.iopi.org. 
Kersten, R. A. \& Silva, S. M. 2002. Florística e estrutura do componente epifítico vascular em floresta ombrófila mista aluvial do rio Barigüi, Paraná, Brasil. Revista Brasileira de Botânica 25(3): 259-267.

Klein, R. M. 1990. Espécies raras ou ameaçadas de extinção do estado de Santa Catarina. Vol. 1. IBGE, Rio de Janeiro. Pp. 185-287.

Leitão-Filho, H. F. 1987. Considerações sobre a florística de florestas tropicais e subtropicais do Brasil. IPEF 35: 41-46.

Leme, E. M. C. 1997. Canistrum, Bromélias da Mata Atlântica. Ed. Salamandra, Rio de Janeiro, 107p.

Leme, E. M. C. 1998. Canistropsis, Bromélias da Mata Atlântica. Ed. Salamandra, Rio de Janeiro, 143p.

Leme, E. M. C. 2000. Nidularium. Bromélias da Mata Atlântica. Ed. Sextante, Rio de Janeiro. 264p.

Leoni, L. S. \& Trindade, T. 2006. Bromeliaceae da Zona da Mata Leste do estado de Minas Gerais. Pabstia 17(2): 1-20.

Lewinsohn, T. M. \& Prado, P. I. 2002. Biodiversidade Brasileira: síntese do estado atual do conhecimento. Contexto. São Paulo. 176p.

Lima, H. C. \& Guedes-Bruni, R. R. 1997. Diversidade de plantas vasculares na Reserva Ecológica de Macaé de Cima. In: Lima, H. C. \& Guedes-Bruni, R. R (orgs.). Serra de Macaé de Cima: Diversidade Florística e Conservação em Mata Atlântica. Instituto de Pesquisas Jardim Botânico do Rio de Janeiro, Rio de Janeiro. Pp. 29-39.

Luther, H. E. 2004. An alphabetical list of bromeliad binomials. $10^{\text {th }}$ ed. The Bromeliad Society International. The Marie Selby Botanical Gardens, Sarasota, 113p.

Luther, H. E. \& Sieff, E. 1994. De Rebus Bromeliacearum I. Selbyana 15: 9-93.

Luther, H. E. \& Sieff, E. 1997. De Rebus Bromeliacearum II. Selbyana 18(1): 103140.
Luther, H. E. \& Sieff, E. 2001. De Rebus Bromeliacearum III. Selbyana 22(1): 34-67.

Marks, K. 2006. An alphabetical list of bromeliad synonyms. The Bromeliad Society International, $77 \mathrm{p}$.

Mamede, M. C. H.; Cordeiro, I. \& Rossi, L. 2001. Flora vascular da Serra da Juréia, Município de Iguape, São Paulo, Brasil. Boletim do Instituto de Botânica 15: 63-124.

Marques, M. C. M. (org.). 1997. Mapeamento da cobertura vegetal e listagem das espécies ocorrentes na área de Proteção Ambiental de Cairuçu, Parati, RJ. Instituto de Pesquisas Jardim Botânico do Rio de Janeiro. Série Estudos e Contribuições 13: 1-96.

Martinelli, G. 1988. Padrões fitogeográficos em Bromeliaceae dos campos de altitude da floresta pluvial tropical costeira do Brasil no estado do Rio de Janeiro. Rodriguésia 66(40): 3-10.

Martinelli, G. 2006. Manejo de populações e comunidades vegetais: um estudo de caso na conservação de Bromeliaceae. In: Rocha, F. D.; Bergallo, H. G.; Sluys, M. V. \& Alves, M. A. S. (eds). Biologia da Conservação: Essências. Ed. Rima, São Paulo. Pp. 479-503.

Mendonça, M. P. \& Lins, L. V. 2000. Introdução. Listas vermelhas: ferramentas para conservação de espécies ameaçadas. In: Mendonça, M. P. \& Lins, L. V. (orgs.). Lista Vermelha das Espécies Ameaçadas de Extinção da Flora de Minas Gerais. Fundação Biodiversitas \& Fundação Zôo-Botânica. Belo Horizonte. Pp. 13-30.

MMA. 1998. Primeiro relatório nacional para a convenção sobre diversidade biológica: Brasil, Brasília, 283p.

Moura, R. L.; Costa, A. F. \& Araujo, D. S. D. 2007. Bromeliaceae das restingas fluminenses: florística e fitogeografia. Arquivos do Museu Nacional 65(4): 139168.

Myers, N.; Mittermeier, R. A.; Fonseca, G. A. B. \& Kent, J. 2000. Biodiversity 
hotspots for conservation priorities. Nature 403: 853-858.

Nunes-Freitas, A. F. 2005. Bromeliáceas da Ilha Grande: variação inter-habitats na composição, riqueza e diversidade da comunidade. Tese de Doutorado. Universidade do Estado do Rio de Janeiro, Rio de Janeiro, 195p.

Oliveira-Filho, A. T. \& Fontes, M. L. A. 2000. Patterns of floristic differentiation among Altantic Forests in Southeastern Brazil and the influence of climate. Biotropica 32(4b): 793-810.

Paula, C. C. 1998. Florística da família Bromeliaceae no Parque Estadual da Serra do Brigadeiro, Minas Gerais, Brasil. Tese de Doutorado. Universidade Estadual Paulista, Rio Claro, 238p.

Pontes, R. A. S. 2005. Bromeliaceae da floresta atlântica no estado da Paraíba, Brasil. Dissertação de Mestrado. Instituto de Pesquisas Jardim Botânico do Rio de Janeiro, Escola Nacional de Botânica Tropical, Rio de Janeiro. Pp 1-80.

Reitz, R. 1983. Bromeliáceas e a MaláriaBromélia Endêmica. In: Reitz, R. (ed.). Flora Ilustrada Catarinense. Herbário Barbosa Rodrigues, Itajaí, Fasc. BROM. 59p.

Rizzini, C. T. 1997. Tratado de fitogeografia do Brasil. $2^{\mathrm{a}}$. ed. Âmbito Cultural Edições, Rio de Janeiro, 747p.

Rocha, C. F. D.; Bergallo, H. G.; van Sluys, M.; Alves, M. A. S. \& Jenkins, C. 2006. Corredores ecológicos e conservação da biodiversidade: um estudo de caso na Mata Atlântica. In: Rocha, F. D.; Bergallo, H. G.; Sluys, M. V. \& Alves, M. A. S. (eds). Biologia da Conservação: Essências. Ed. Rima, São Paulo. Pp. 317342.

Rocha, C. F. D.; Cogliatti-Carvalho, L. \& Almeida, D. R. 1997. Bromélias: ampliadoras de biodiversidade. Bromélia 4(4): 7-10.

Rogalski, J. M. \& Zanin, E. M. 2003. Composição florística de epífitos vasculares no estreito de Augusto César, Floresta Estacional
Decidual do Rio Uruguai, RS, Brasil. Revista Brasileira de Botânica 26(4): 551-556.

Sanderson, J.; Alger, K.; Fonseca, G. A. B.; Galindo-Leal C.; Inchausty, V. H. \& Morrinson, K. 2003. Biodiversity conservation corridors: planning, implementing and monitoring sustainable landscape. Conservation International, Washington, 41p.

Saunders, D. A. \& Hobbs, R. J. 1991. The role of corridors in conservation: what do we know and where do we go? In: Saunders, D. A. \& Hobbs, R. J. (eds.). Nature Conservation 2: the role of corridors. Surrey Beatty \& Sons. Chiping Norton, New S.Wales. Pp. 421-427.

SEMA. 1995. Lista vermelha de plantas ameaçadas de extinção no estado do Paraná. SEMA/GTZ, Curitiba, 139p.

SEMA. 2002. Lista oficial das espécies plantas ameaçadas de extinção no estado do Rio Grande do Sul. Disponível em: http:// www.sema.rs.gov.br/sema/html/pdf/ especies-ameacadas.

SEMA. 2004. Lista oficial das espécies da flora do estado de São Paulo ameaçadas de extinção. Diário Oficial do Estado de São Paulo, Resolução SMA 48. http:// www.ibot.sp.gov.br/resolucao_sma48/ resolucao48.htm.

Siqueira-Filho, J. A. \& Leme, E. M. C. 2006. Fragmentos de Mata Atlântica do Nordeste. Biodiversidade, Conservação e suas Bromélias. Andréa Jakobson Estúdio, Rio de Janeiro, 416p.

Siqueira-Filho, J. A.; Santos, A. M. M.; Leme, E. M. C. \& Cabral, J. S. 2006. Fragmentos da Mata Atlântica de Pernambuco e Alagoas e suas bromélias: distribuição, composição riqueza e conservação. In: Siqueira-Filho, J. A. \& Leme, E. M. C. (eds.). Fragmentos de Mata Atlântica do Nordeste. Biodiversidade, Conservação e suas Bromélias. Andrea Jakobson Estúdio, Rio de Janeiro. Pp. 101-131. 
Smith, L. B. 1955. The Bromeliaceae of Brazil. Smithsonian Miscellaneous Collections 126(1): 1-290.

Smith, L. B. \& Downs, R. J. 1974. Pitcairnioideae (Bromeliaceae). Flora Neotropica Monograph 14(1): 1- 658.

Smith, L. B. \& Downs, R. J. 1977. Tillandsioideae (Bromeliaceae). Flora Neotropica Monograph 14(2): 663-1492.

Smith, L. B. \& Downs, R .J. 1979. Bromelioideae (Bromeliaceae). Flora Neotropica Monograph 14(3): 1493-2141.

SOS MATA ATLÂNTICA/INPE. 2000. Atlas dos remanescentes florestais e ecossistemas associados da Mata Atlântica. Fundação SOS Mata Atlântica, São Paulo.

Sousa, G. M. 2004a. Revisão taxonômica de Aechmea Ruiz \& Pavon subg. Chevaliera (Gaudich. ex Beer) Baker Bromelioideae - Bromeliaceae. Tese de Doutorado. Universidade de São Paulo, São Paulo, 185p.

Sousa, G. M. \& Wanderley, M. G. L. 2000. Aechmea Ruiz \& Pav. (Bromeliaceae) do estado de Pernambuco, Brasil. Acta Botânica Brasílica 14(1): 77-97.

Sousa, L. O. 2004b. Revisão taxonômica e filogenia do gênero Lymania Read. (Bromelioideae-Bromeliaceae). Dissertação de Mestrado. Universidade Federal do Rio de Janeiro, Rio de Janeiro, 102p.

SPECIES2000. 2006. The catalogue of life: http://species2000.org Acessado em 1/9/ 2007.

Tabarelli, M.; Aguiar, A. V.; Grillo, A. S. \& Santos, A. M. M. 2006. Fragmentação e perda de habitats na Mata Atlântica ao norte do rio São Francisco. In: SiqueiraFilho, J. A. \& Leme, E. M. C. Fragmentos de Mata Atlântica do Nordeste. Biodiversidade, Conservação e suas Bromélias. Andréa Jakobson Estúdio, Rio de Janeiro. Pp. 81-99.

Tardivo, R. C. 2002. Revisão taxonômica de Tillandsia L. subgênero Anoplophytum (Beer) Baker (Bromeliaceae). Tese de
Doutorado. Universidade de São Paulo, São Paulo, 243p.

Urban, D. L. \& Shugart, H. H. Jr. 1986. Avian demography in mosaic landscapes: Modelling paradigm and preliminary. In: Verner, M. L.; Morrison, M. L. \& Ralph, C. J. (eds). Wildlife 2000. Modelling habitat relationships of terrestrial vertebrates. University Wiscosin Press, Wiscosin. Pp. 273-279.

Veloso, H. P.; Rangel-Filho, A. L. R. \& Lima, J. C. A. 1991. Classificação da vegetação brasileira, adaptada a um sistema universal. IBGE, Rio de Janeiro, 123 p.

Versieux, L. M. \& Wendt, T. 2006. Checklist of Bromeliaceae of Minas Gerais, Brazil, with notes on taxonomy and endemism. Selbyana 27(2): 107-146.

Versieux, L. M. \& Wendt, T. 2007. Bromeliaceae diversity and conservation in Minas Gerais state, Brazil. Biodiversity and Conservation 16: 2989-3009.

Vidal, U. A. 1995. A família Bromeliaceae na Reserva Ecológica Rio das Pedras, Mangaratiba, Rio de Janeiro. Dissertação de Mestrado. Universidade Federal do Rio de Janeiro, Rio de Janeiro, 156p.

Vieira, C. M. 2006. Quesnelia Gaudich. (Bromelioideae: Bromeliaceae) do estado do Rio de Janeiro, Brasil. Pesquisas, Botânica 57: 7-102.

Wanderley, M. G. L. \& Mollo, L. 1992. Bromeliaceae. In: Melo, M. M. R. F.; Barros, F.; Chiea, S. A. C.; Wanderley, M. G. L.; Jung-Mendaçolli, S. L. \& Kirizawa, M. (eds.). Flora Fanerogâmica da Ilha do Cardoso. Vol. 3. Instituto de Botânica, São Paulo. Pp. 89-140.

Wendt, T. 1994. Pitcairnia L'Héritier (Bromeliaceae) of Rio de Janeiro State, Brazil. Selbyana 15: 66-78.

Wendt, T. 1997. A review of the subgenus Pothuava (Baker) Baker of Aechmea Ruiz \& Pav. (Bromeliaceae) in Brazil. Botanical Journal of the Linnean Society 125: 245-271. 
With, K. A.; Gardner, R. H. \& Turner, M. G. 1997. Landscape connectivity and population distributions in heterogeneous environments. Oikos 78: 151-169.
Workshop Biodiversitas. 2005. Revisão da Lista da Flora Brasileira Ameaçada de Extinção. http://www.biodiversitas.org.br/ florabr/. Acessado em 1/9/2006. 